\title{
Development of a species-specific model of cerebral hemodynamics
}

\author{
SILVIA DAUN ${ }^{*}$ and THORSTEN TJARDES $\ddagger$ \\ $\dagger$ Department of Mathematics, University of Cologne, Weyertal 86-90, Cologne D-50931, Germany \\ $\ddagger$ Department of Trauma and Orthopaedic Surgery, University of Witten-Herdecke, Merheim Medical Center, Ostmerheimerstr. 200, Cologne D-51109, \\ Germany
}

(Received 23 February; revised 5 July 2005; accepted 27 October 2005)

\begin{abstract}
In this paper, a mathematical model for the description of cerebral hemodynamics is developed. This model is able to simulate the regulation mechanisms working on the small cerebral arteries and arterioles, and thus to adapt dynamically the blood flow in brain. Special interest is laid on the release of catecholamines and their effect on heart frequency, cardiac output and blood pressure. Therefore, this model is able to describe situations of severe head injuries in a very realistic way.
\end{abstract}

Keywords: Cerebral hemodynamics; Regulation mechanisms; Catecholamines; Cardiac output

\section{Introduction}

Cerebral perfusion is a critical parameter in many clinical situations, e.g. cerebral infarction or head injury. Many of these conditions have been investigated extensively in experimental and clinical studies with respect to a wide variety of clinical and physiological parameters. In the past decades, the key mechanisms involved in the regulation of cerebral perfusion have been identified. However, it is a well-known problem of classical reductionist-experimental approaches that different physiological parameters cannot be evaluated simultaneously. Consequently, there is very little knowledge concerning the in-situ consequences of interactions between different physiological regulatory systems. The therapeutic interventions based on single parameter mechanisms, e.g. hyperventilation to reduce arterial $p \mathrm{CO}_{2}$, have not proven successful as "single-agent" therapy to improve the outcome in head injured patients. Physiologic data from patients in a clinical context are difficult to obtain as these patients are often in a life threatening condition. Given the high degree of susceptibility of traumatic brain injuries to any external stimuli extensive interventions for data acquisition are ethically questionable as these interventions might affect the outcome. Data collection in healthy control groups is even more problematic with respect to possible complications due to the highly invasive nature of measurement technology. Additionally, the varying extend of traumatic brain injury, comorbidities or additional injuries result in very heterogeneous patient populations, i.e. the data pool for modelling will be the sum total of very different clinical entities that might display differing behaviour. Mathematical approaches do not suffer from these intrinsic problems. In the past different mathematical models of the cerebral circulation or distinct parts of the regulatory systems have been developed. However, the two major drawbacks of these models are a lack of anatomical coherence and the missing species specificity. For these reasons it has been difficult to validate these models experimentally. Consequently, the ultimate aim of all modelling approaches in clinical medicine, i.e. to arrive at a level of understanding of physiological processes sufficiently profound to derive rules to influence the in-vivo system systematically (i.e. therapeutically), has not yet been reached. The model presented in this paper is, therefore, strictly species specific as almost exclusively data from experiments with Sprague-Dawley rats have been used for parameter estimation. To facilitate the experimental validation, as well as model based experimental interventions the structure of the model is kept very close to the anatomical structure in-vivo.

The basic idea of this model is the treatment of blood flow through extra- and intracranial vessels as a hydraulic circuit. This is a standard way to describe blood flow dynamics as can be found in references [1-4]. The advantage of this approach is the portability of the fundamental laws of electric circuits to hydraulic circuits, like Ohm's and Kirchhoff's law.

*Corresponding author. Email: sdaun@mi.uni-koeln.de

Journal of Theoretical Medicine

ISSN 1027-3662 print/ISSN 1607-8578 online (c) 2005 Taylor \& Francis

http://www.tandf.co.uk/journals

DOI: $10.1080 / 10273660500441324$ 


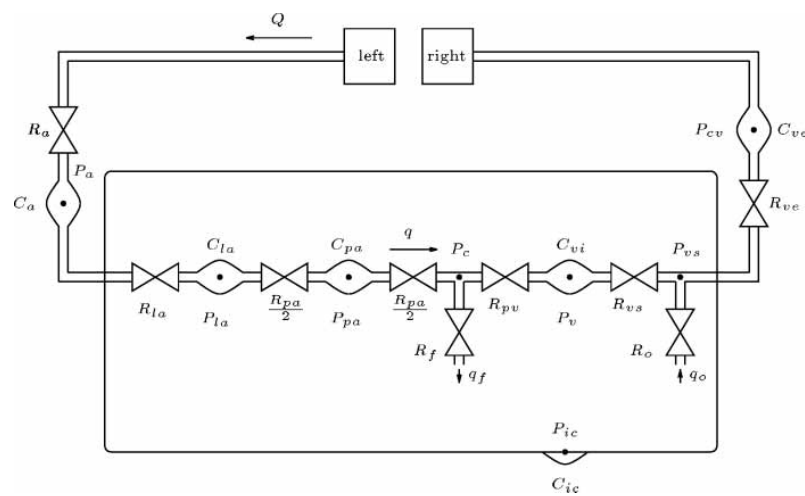

Figure 1. Biomechanical analog of the mathematical model, in which resistances are represented with restrictions and compliances with bulges. $P_{\mathrm{a}}$, systemic arterial pressure; $R_{\mathrm{a}}$ and $C_{\mathrm{a}}$, systemic arterial resistance and compliance; $Q$, cardiac output from the left heart, only a fraction of it goes into head; $P_{\mathrm{la}}, R_{\mathrm{la}}$ and $C_{\mathrm{la}}$, pressure, resistance and compliance of large intracranial arteries, respectively; $P_{\mathrm{pa}}, R_{\mathrm{pa}}$ and $C_{\mathrm{pa}}$, pressure, resistance and compliance of pial arterioles, respectively; $P_{\mathrm{c}}$, capillary pressure; $q$, tissue cerebral blood flow; $R_{\mathrm{pv}}$, resistance of proximal cerebral veins; $C_{\mathrm{vi}}$, intracranial venous compliance; $P_{\mathrm{v}}$, cerebral venous pressure; $P_{\mathrm{vs}}$ and $R_{\mathrm{vs}}$, sinus venous pressure and resistance of the terminal intracranial veins, respectively; $q_{\mathrm{f}}$ and $q_{\mathrm{o}}$, cerebrospinal fluid flow into and out of the craniospinal space, respectively; $R_{\mathrm{f}}$ and $R_{\mathrm{o}}$, inflow and outflow resistance; $P_{\mathrm{ic}}$ and $C_{\mathrm{ic}}$, intracranial pressure and compliance, respectively; $P_{\mathrm{cv}}$, central venous pressure, $R_{\mathrm{ve}}$ and $C_{\mathrm{ve}}$, resistance and compliance of the extracranial veins.

The hydraulic circuit was extended by several physiological mechanisms. First work in this direction was done by Ursino et al. [1] by including the autoregulation and the $\mathrm{CO}_{2}$ reactivity. In this work, the following additional features are treated to get a more realistic and physiologically applicable model (figure 1):

- the extracranial pathways which close the circulation of blood;

- the pulsatility of blood flow, which is given by using a periodic function for the cardiac output $Q$ as input to the systemic circulation;

- the regulation mechanism, which describes the dependence of cerebral blood flow on the production of nitric oxide (NO) at the endothelial cells of the small cerebral arteries and arterioles (NO reactivity);

- the interaction between $\mathrm{CO}_{2}$ and $\mathrm{NO}$ reactivity;

- the description of the release of catecholamines into the blood and its impact on heart frequency, cardiac output and thus blood pressure.

The paper is organized as follows: in section 2, a qualitative model description is given. The process of parameter estimation is described in section 3 and numerical simulations and validation results are shown in section 4. In the last section, the mathematical model is discussed and an outlook is given.

\section{Qualitative model description}

The model is qualitatively presented, with attention focused on its new aspects.

\subsection{Extracranial arterial pathways}

The work of Ursino et al. [2] is used as the basic model for the new investigations. There only the cerebral hemodynamics are considered and the blood pressure $P_{\mathrm{a}}$ is chosen as a constant input parameter for the cerebral blood circulation. In this work, the extracranial arterial pathways are also modelled and thus the arterial blood pressure is no constant parameter but depends on time $t$, cardiac output $Q$ and thus on cardiac parameters.

The segment of the extracranial arteries from the left heart to the large cerebral arteries is, like the other segments of the model, described by the hydraulic resistance $R_{\mathrm{a}}$ and the hydraulic compliance $C_{\mathrm{a}}$. The amount of blood ejected from the heart into the aorta in a certain time is modelled by a function $Q$, which will be described later. Because of the theory of hydraulic circuits, blood volume changes $\mathrm{d} V / \mathrm{d} t$ in the extracranial and intracranial arteries and veins are given by the difference of blood flow into and out of these vessels. The compliances $C$ are synonymous with the storage capacities of the arteries and veins. Therefore, the blood volume changes $\mathrm{d} V_{\mathrm{a}} / \mathrm{d} t$ are given by the difference of the blood flow into the aorta $(Q)$ minus the systemic blood flow out of the aorta through all organs of the body $\left(\left(P_{\mathrm{a}}-P_{\mathrm{cv}}\right) / R_{\mathrm{s}}\right)$ :

$$
\frac{\mathrm{d} V_{\mathrm{a}}}{\mathrm{d} t}=C_{\mathrm{a}} \frac{\mathrm{d} P_{\mathrm{a}}}{\mathrm{d} t}=Q-\frac{P_{\mathrm{a}}-P_{\mathrm{cv}}}{R_{\mathrm{s}}}
$$

where $Q$ is cardiac output, $P_{\mathrm{a}}$ arterial, $P_{\mathrm{cv}}$ central venous pressure and $R_{\mathrm{s}}$ systemic resistance. The blood flow through the vessels is calculated by Ohm's law. Since $P_{\mathrm{cv}} \ll P_{\mathrm{a}}$ changes in blood pressure $\mathrm{d} P_{\mathrm{a}} / \mathrm{d} t$ are approximately given by

$$
\frac{\mathrm{d} P_{\mathrm{a}}}{\mathrm{d} t}=\frac{1}{C_{\mathrm{a}}}\left(Q-\frac{P_{\mathrm{a}}}{R_{\mathrm{s}}}\right) .
$$

The fraction of cardiac output $Q$ which goes into head is then given by $\left(P_{\mathrm{a}}-P_{\mathrm{la}}\right) / R_{\mathrm{la}}$ and the value of the compliance $C_{\mathrm{a}}$ is corresponding to [5] $C_{\mathrm{a}}=0.0042$ $\mathrm{ml} / \mathrm{mm} \mathrm{Hg}$.

\subsection{Cardiac output}

The model function for cardiac output $Q$, developed by Stevens et al. [6], is used to get a pulsatile blood flow throughout the circulatory system. The cardiac output $Q$ is modelled by defining an interior function which oscillates with the frequency of the heart pulse and an envelope function for these interior oscillations. The product of these two functions is then normalized and the parameters are calibrated with physical rat data. The provisional flow function $Q_{3}(t, n, \Phi)$ is then given by

$$
Q_{3}(t, n, \Phi)=Q_{1}(t, n) \cdot Q_{2}(t, \Phi)
$$



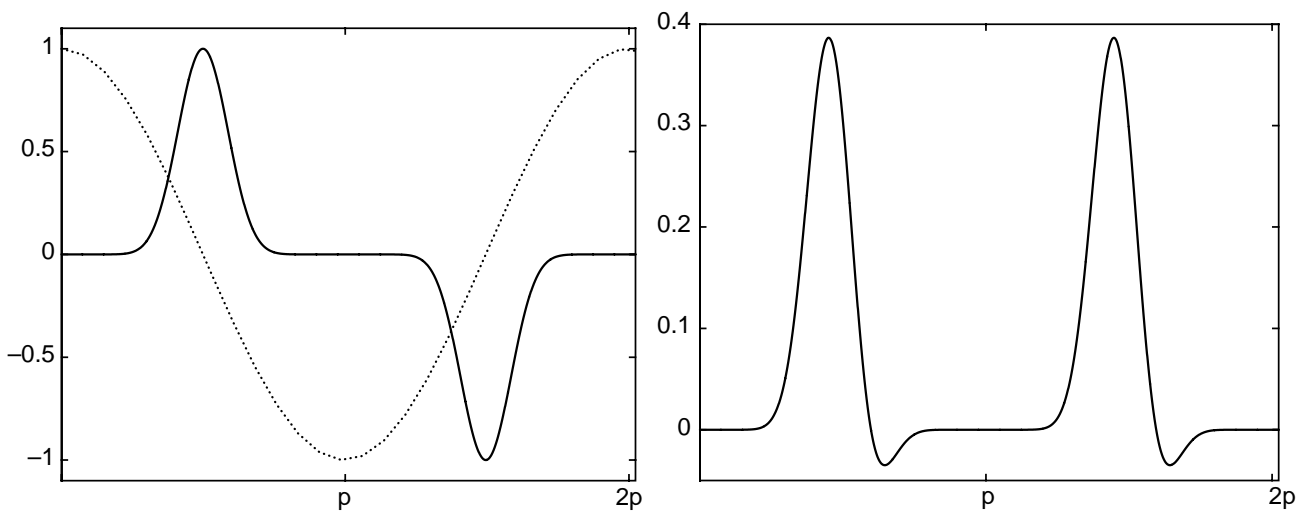

Figure 2. Left: The envelope function $Q 1$ (solid curve) and the interior function $Q 2$ (dashed curve) for $n=13$ and $\Phi=0$. Right: The flow function $Q_{3}(t, 13, \pi / 10)$

where the envelope function is defined by

$$
Q_{1}(t, n)=\sin ^{n}(\omega t) \text { with } n \text { odd }
$$

and the interior function has the form

$$
Q_{2}(t, \Phi)=\cos (\omega t-\Phi)
$$

with $\omega$ one half of the basic frequency of the heart pulse and $\Phi$ a suitable phase angle. Generally $\Phi$ lies in the range $0<\Phi \leq \pi / 2$. If $\Phi=0$, cardiac outflow will equal backflow. There is nearly zero backflow if $\Phi>\pi / 6$. For $n=13$ and $\Phi=0$, these two functions are shown in figure 2.

The $Q$ must be normalized and calibrated to produce a good model function for cardiac output. The set of calibration parameters for this model function includes the stroke volume $\nu$, the heart rate $b$, and the phase angle $\Phi$. To fit the experimental data given by reference [5], the parameters are chosen as follows:

the heart rate $b=378 / 60$ beats per second, the mean value for cardiac output $\bar{Q}=\nu b=70 / 60 \mathrm{ml} \mathrm{s}^{-1}$ thus the stroke volume $\nu=\bar{Q} / b=0.1852 \mathrm{ml}$ per second the phase angle $\Phi=\pi / 10$.

Once appropriate values of these calibration parameters are chosen, it is possible to determine the period $p=1 / b$ of the cycle and the frequency $\omega=\pi / p$.

By normalizing the model function $Q_{3}$ so that the total outflow over one period equals $\nu$ one gets

$$
\begin{aligned}
Q(t, n, \Phi) & =\frac{\nu}{A(n, \Phi)} Q_{3}(t, n, \Phi) \\
& =\frac{\nu}{A(n, \Phi)} \sin ^{n}(\omega t) \cos (\omega t-\Phi)
\end{aligned}
$$

where

$$
\bar{A}(n, \Phi)=\int_{0}^{p} Q_{3}(t, n, \Phi) \mathrm{d} t .
$$

With the relation $\omega=\pi / p$ and noting that

$$
\begin{aligned}
\bar{A}(n, \Phi) & =\int_{0}^{\pi} \sin ^{n}(t) \cos (t-\Phi) \mathrm{d} t \\
& =\frac{\sqrt{\pi} \Gamma\left(1+\frac{n}{2}\right) \sin (\Phi)}{\Gamma\left(\frac{3+n}{2}\right)}
\end{aligned}
$$

with $\Gamma$ the Euler gamma function, one gets

$$
\begin{aligned}
A(n, \Phi) & =\int_{0}^{p} Q_{3}(t, n, \Phi) \mathrm{d} t \\
& =\int_{0}^{\frac{\pi}{\omega}} \sin ^{n}(\omega t) \cos (\omega t-\Phi) \mathrm{d} t=\frac{\bar{A}(n, \Phi)}{\omega} .
\end{aligned}
$$

An example for $Q(t, n, \Phi)$ is given in figure 3. The narrowness of the output function $Q$ is determined by the choice of $n$. A large $n$ represents a small systole period. Using a value of $n=13$ results in a systole period approximately $1 / 3$ of the cardiac cycle, consistent with values given by many of the standard texts in physiology.

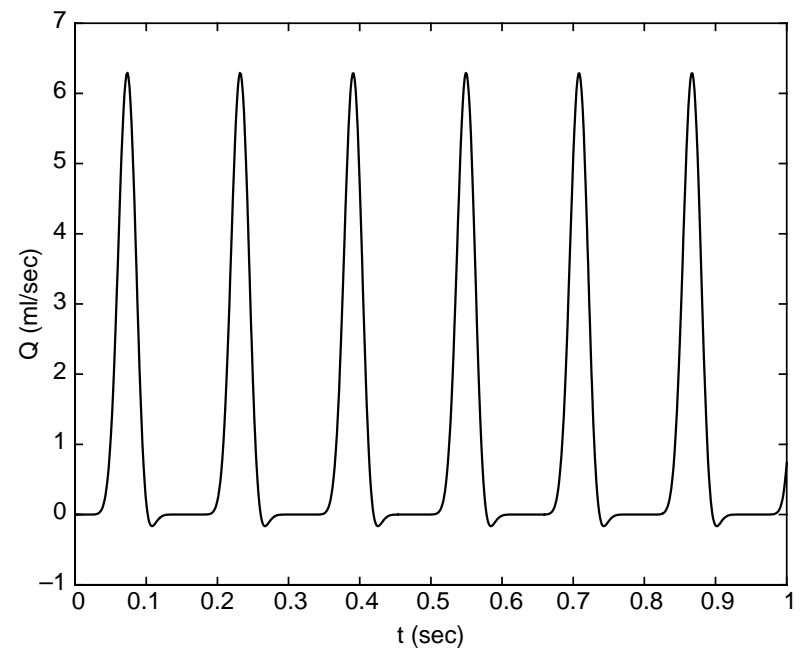

Figure 3. Cardiac output $Q$ of rat is simulated by the model function with heart rate $b=378 / 60$ beats per second, stroke volume $\nu=$ $0.1852 \mathrm{ml}$ per beat, $n=13$, and $\Phi=\pi / 10$. 


\subsection{Intracranial hemodynamics}

The Monro-Kellie doctrine implies that any volume variation in an intracranial compartment causes a compression or dislocation of the other volumes. These changes in the compartments are accompanied by an alteration in intracranial pressure $P_{\text {ic }}$. The intracranial compliance $C_{\mathrm{ic}}$, which represents the capacity of the craniospinal system to store a volume load, is according to Ursino et al. [2] assumed to be inversely proportional to intracranial pressure through a constant parameter

$$
C_{\mathrm{ic}}=\frac{1}{k_{E} \cdot P_{\mathrm{ic}}} \text {. }
$$

In this model, volume changes in the craniospinal space are ascribed to four compartments: large and middle cerebral arteries $\mathrm{d} V_{\mathrm{la}} / \mathrm{d} t$, pial arteries and arterioles $\mathrm{d} V_{\mathrm{pa}} / \mathrm{d} t$, cerebral veins $\mathrm{d} V_{\mathrm{v}} / \mathrm{d} t$, and the $\mathrm{H}_{2} \mathrm{O}$ compartment $\mathrm{d} V_{\mathrm{H}_{2} \mathrm{O}} / \mathrm{d} t$. According to the Monro-Kellie doctrine the following conservation equation holds

$$
C_{\mathrm{ic}} \cdot \frac{\mathrm{d} P_{\mathrm{ic}}}{\mathrm{d} t}=\frac{\mathrm{d} V_{\mathrm{la}}}{\mathrm{d} t}+\frac{\mathrm{d} V_{\mathrm{pa}}}{\mathrm{d} t}+\frac{\mathrm{d} V_{\mathrm{v}}}{\mathrm{d} t}+\frac{\mathrm{d} V_{\mathrm{H}_{2} \mathrm{O}}}{\mathrm{d} t}
$$

with time $t$. The biomechanical analog in figure 1 represents the four intracranial compartments considered in the model, together with the extracranial arterial and venous pathways.

\subsection{Large and middle cerebral arteries}

The first intracranial segment of the model represents the circulation of blood in the large and middle cerebral arteries. The hemodynamic is described by a hydraulic resistance $R_{\text {la }}$ and a hydraulic compliance $C_{\text {la }}$. In contrast to the model of Ursino et al. [2] changes in the storage capacity $C_{\mathrm{la}}$ and thus on the blood volume $V_{\text {la }}$ and the pressure $P_{\text {la }}$ are modelled. The changes in volume in this segment $\mathrm{d} V_{\mathrm{la}} / \mathrm{d} t$ are given by

$$
\frac{\mathrm{d} V_{\mathrm{la}}}{\mathrm{d} t}=\frac{P_{\mathrm{a}}-P_{\mathrm{la}}}{R_{\mathrm{la}}}-\frac{P_{\mathrm{la}}-P_{\mathrm{pa}}}{R_{\mathrm{pa}} / 2}
$$

where $P_{\mathrm{pa}}$ and $R_{\mathrm{pa}}$ are pressure and resistance of the pial arteries and arterioles, respectively.

Because the impact of the cerebrovascular regulation mechanisms on these intracranial arteries is very small, the resistance $R_{\mathrm{la}}$ is assumed to be constant. Further on, volume changes in this compartment depend only on changes in transmural pressure $\left(P_{\text {la }}-P_{\text {ic }}\right)$ and not on changes in compliance $C_{\text {la }}$, since these vessels behave passively. Thus the following equation holds

$$
\frac{\mathrm{d} V_{\mathrm{la}}}{\mathrm{d} t}=C_{\mathrm{la}}\left(\frac{\mathrm{d} P_{\mathrm{la}}}{\mathrm{d} t}-\frac{\mathrm{d} P_{\mathrm{ic}}}{\mathrm{d} t}\right) .
$$

With these two equations in mind one gets a differential equation which describes pressure changes $\mathrm{d} P_{1 \mathrm{a}} / \mathrm{d} t$ in the large and middle cerebral arteries:

$$
\frac{\mathrm{d} P_{\mathrm{la}}}{\mathrm{d} t}=\frac{1}{C_{\mathrm{la}}}\left(\frac{P_{\mathrm{a}}-P_{\mathrm{la}}}{R_{\mathrm{la}}}-\frac{P_{\mathrm{la}}-P_{\mathrm{pa}}}{R_{\mathrm{pa}} / 2}\right)+\frac{\mathrm{d} P_{\mathrm{ic}}}{\mathrm{d} t} .
$$

The compliance of these vessels is assumed to be inversely proportional to the transmural pressure

$$
C_{\mathrm{la}}=\frac{k_{C_{\mathrm{la}}}}{P_{\mathrm{la}}-P_{\text {ic }}}
$$

with $k_{C_{\mathrm{la}}}$ the proportionality constant.

\subsection{Pial arteries and arterioles}

In this compartment of the model all sections of the cerebrovascular bed directly under the control of the regulatory mechanisms are comprised. This pial arterial segment is described by a hydraulic resistance $R_{\mathrm{pa}}$ and a hydraulic compliance $C_{\mathrm{pa}}$. Both of these parameters are regulated by cerebrovascular control mechanisms. The two equations which describe the changes in volume $\mathrm{d} V_{\mathrm{pa}} / \mathrm{d} t$ in this segment and the calculation of the pressure at the cerebral capillaries $P_{\mathrm{c}}$ (applying Kirchhoff's law) are given in reference [2].

With these three equations the pressure change $\mathrm{d} P$ pa $/ \mathrm{d} t$ in the pial arterial compartment is described by

$$
\begin{aligned}
\frac{\mathrm{d} P_{\mathrm{pa}}}{\mathrm{d} t}= & \frac{1}{C_{\mathrm{pa}}}\left[\frac{P_{\mathrm{la}}-P_{\mathrm{pa}}}{R_{\mathrm{pa}} / 2}-\frac{P_{\mathrm{pa}}-P_{\mathrm{c}}}{R_{\mathrm{pa}} / 2}-\frac{\mathrm{d} C_{\mathrm{pa}}}{\mathrm{d} t}\left(P_{\mathrm{pa}}-P_{\mathrm{ic}}\right)\right] \\
& +\frac{\mathrm{d} P_{\mathrm{ic}}}{\mathrm{d} t} .
\end{aligned}
$$

\subsection{Intracranial and extracranial venous circulation}

The intracranial vascular bed of the veins is described by a series arrangement of two segments. The first, from the small postcapillary venules to the large cerebral veins, contains the resistance $R_{\mathrm{pv}}$ and the venous compliance $C_{\mathrm{vi}}$. Corresponding to reference [2], the compliance is calculated by

$$
C_{\mathrm{vi}}=\frac{k_{\mathrm{ven}}}{P_{\mathrm{v}}-P_{\mathrm{ic}}-P_{\mathrm{v} 1}},
$$

where $k_{\mathrm{ven}}$ is a constant parameter and $P_{v 1}$ represents the transmural pressure value at which cerebral veins collapse.

Using the equations defined in reference [2], which describe the volume changes $\mathrm{d} V_{\mathrm{v}} / \mathrm{d} t$ of this venous compartment, the pressure changes $\mathrm{d} P P_{\mathrm{v}} / \mathrm{d} t$ are given by

$$
\frac{\mathrm{d} P_{\mathrm{v}}}{\mathrm{d} t}=\frac{1}{C_{\mathrm{vi}}}\left(\frac{P_{\mathrm{c}}-P_{\mathrm{v}}}{R_{\mathrm{pv}}}-\frac{P_{\mathrm{v}}-P_{\mathrm{vs}}}{R_{\mathrm{vs}}}\right)+\frac{\mathrm{d} P_{\mathrm{ic}}}{\mathrm{d} t},
$$

where $R_{\mathrm{vs}}$ is the resistance of the terminal intracranial veins and $P_{\mathrm{vs}}$ the pressure at the dural sinuses.

The second segment represents the terminal intracranial veins (e.g. lateral lakes). During intracranial hypertension 
these vessels collide or narrow at their entrance into the dural sinuses, with a mechanism similar to that of a starling resistor (cf. [2]). Because of this phenomenon the resistance $R_{\mathrm{vs}}$ depends on the pressures of the system in the following way:

$$
R_{\mathrm{vs}}=\frac{P_{\mathrm{v}}-P_{\mathrm{vs}}}{P_{\mathrm{v}}-P_{\mathrm{ic}}} \cdot R_{\mathrm{vs} 1}
$$

where $R_{\mathrm{vs} 1}$ represents the terminal vein resistance when $P_{\mathrm{ic}}=P_{\mathrm{vs}}$.

In contrast to the model of Ursino et al. [2] the sinus venous pressure $P_{\mathrm{vs}}$ is not assumed to be constant, but depends on time and the other pressures of the system and is calculated by Kirchhoff's law

$$
\frac{P_{\mathrm{v}}-P_{\mathrm{vs}}}{R_{\mathrm{vs}}}+q_{\mathrm{o}}=\frac{P_{\mathrm{vs}}-P_{\mathrm{cv}}}{R_{\mathrm{ve}}} .
$$

Since the water backflow at the dural sinuses $q_{\mathrm{o}}$ is negligible in comparison to the blood flows, it is assumed to be zero.

The extracranial venous circulation from the dural sinuses through the vena cava back to the heart is described by the hydraulic resistance $R_{\mathrm{ve}}$ and the hydraulic compliance $C_{\mathrm{ve}}$. Because no mechanisms acting on these blood vessels are taken into account, these parameters are assumed to be constant.

\section{$2.7 \mathrm{H}_{2} \mathrm{O}$ compartment}

Under clinical aspects the formation of cerebral edema after head injury has to be described by the model. This mechanism is reproduced by water outflow at the capillaries into the craniospinal space and water backflow at the dural sinuses. It is assumed that the two processes are passive and unidirectional, thus the following equations hold:

$$
\begin{gathered}
q_{f}=\left\{\begin{array}{cl}
\frac{P_{\mathrm{c}}-P_{\mathrm{ic}}}{R_{f}} & \text { if } P_{\mathrm{c}}>P_{\mathrm{ic}} \\
0 & \text { else }
\end{array}\right. \\
q_{\mathrm{o}}=\left\{\begin{array}{cl}
\frac{P_{\mathrm{ic}}-P_{\mathrm{vs}}}{R_{\mathrm{o}}} & \text { if } P_{\mathrm{ic}}>P_{\mathrm{vs}} \\
0 & \text { else. }
\end{array}\right.
\end{gathered}
$$

The case of a severe cerebral edema is simulated by decreasing the outflow resistance $R_{f}$, thus increasing the outflow $q_{f}$, whereas the backflow $q_{\mathrm{o}}$ is assumed to be constant and small all the time. Under physiological conditions $q_{f}$ and $q_{\mathrm{o}}$ are approximately zero. Changes in volume in this $\mathrm{H}_{2} \mathrm{O}$ compartment are given by $\mathrm{d} V_{\mathrm{H}_{2} \mathrm{O}} / \mathrm{d} t=q_{f}-q_{\mathrm{o}}$.

\subsection{Cerebrovascular regulation mechanisms}

Cerebrovascular regulation mechanisms work by modifying the resistance $R_{\mathrm{pa}}$ and the compliance $C_{\mathrm{pa}}$ (and hence the blood volume) in the pial arterial-arteriolar vasculature.

In this section, three mechanisms are considered which regulate cerebral blood flow. The effects of two of them, like autoregulation and $\mathrm{CO}_{2}$ reactivity, are described in [2]. One new cerebrovascular regulation mechanism, the NO reactivity, is inserted into the model and its effect on the pial arterial compliance is modelled by using the given idea of a sigmoidal relationship of the whole regulation process.

2.8.1 Autoregulation. The cerebral autoregulation describes the ability of certain vessels to keep the cerebral blood flow (CBF) relatively constant despite changes in perfusion pressure.

As you can see in the upper branch of figure 4 , it is assumed that autoregulation is activated by changes in CBF. The impact of this mechanism on the pial arterial vessels is described by a first-order low-pass filter dynamic with time constant $\tau_{\text {aut }}$ and gain $G_{\text {aut }}$ (cf. [2])

$$
\tau_{\text {aut }} \frac{\mathrm{d} x_{\text {aut }}}{\mathrm{d} t}=-x_{\text {aut }}+G_{\text {aut }}\left(\frac{q-q_{n}}{q_{n}}\right),
$$

where $q$ is the measured $\mathrm{CBF}$ and $q_{n}$ the cerebral blood flow under basal conditions.

The cerebral blood flow $q$ can be calculated by Ohm's law

$$
q=\frac{P_{\mathrm{pa}}-P_{\mathrm{c}}}{R_{\mathrm{pa}} / 2}
$$

With this relation, we get a basal value for blood flow through the pial arteries of $q_{n}=0.1696 \mathrm{ml} \mathrm{s}^{-1}$. The value of the gain $G_{\text {aut }}$ is given by fitting the autoregulation curve of [7].

2.8.2 $\mathrm{CO}_{2}$ reactivity. The $\mathrm{CO}_{2}$ reactivity describes the dependence of cerebral blood flow on arterial $\mathrm{CO}_{2}$ pressure $P_{a \mathrm{CO}_{2}}$.

The branch in the middle of figure 4 represents the $\mathrm{CO}_{2}$ reactivity, which is activated by changes in $P_{a \mathrm{CO}_{2}}$ and described by a first-order low-pass filter dynamic with time constant $\tau_{\mathrm{CO}_{2}}$ and gain $G_{\mathrm{CO}_{2}}$ (cf. [2])

$$
\tau_{\mathrm{CO}_{2}} \frac{\mathrm{d} x_{\mathrm{CO}_{2}}}{\mathrm{~d} t}=-x_{\mathrm{CO}_{2}}+G_{\mathrm{CO}_{2}} A_{\mathrm{CO}_{2}} \log 10\left(\frac{P_{a \mathrm{CO}_{2}}}{P_{\mathrm{aCO}_{2} n}}\right) \text {, }
$$

where $P_{\mathrm{aCO}_{2} n}$ is the $\mathrm{CO}_{2}$ pressure under basal conditions, corresponding to [8] it is $P_{\mathrm{aCO}_{2} n}=33 \mathrm{~mm} \mathrm{Hg} . A_{\mathrm{CO}_{2}}$ is a corrective factor, which will be described later. The value of the gain $G_{\mathrm{CO}_{2}}$ is obtained by fitting the data of Iadecola et al. [9].

2.8.3 NO reactivity. The NO reactivity describes the dependence of cerebral blood flow on the production rate of NO at the endothelial cells of the pial vessels $q_{\mathrm{NO}}$. 


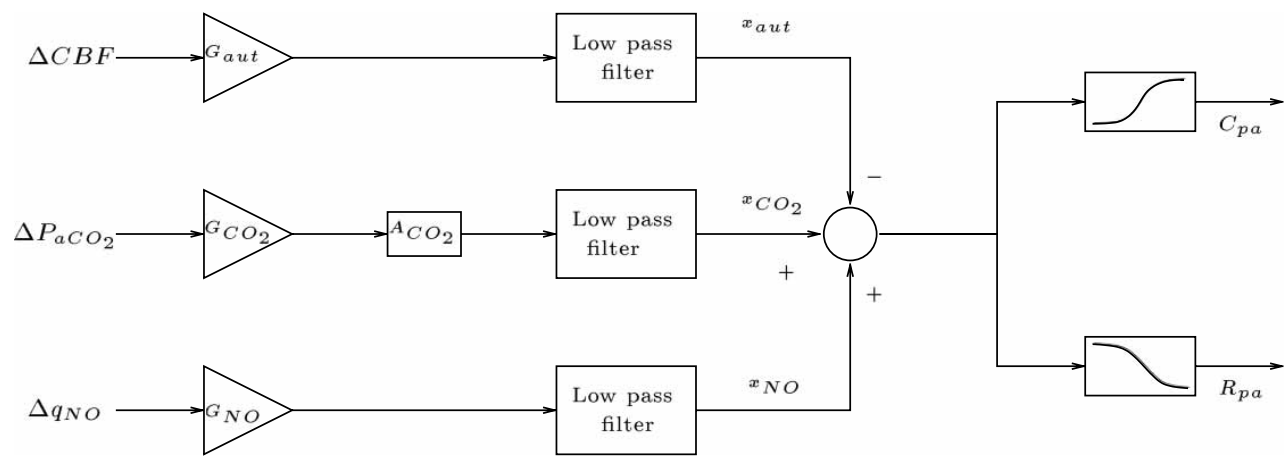

Figure 4. Block diagram describing the action of cerebrovascular regulation mechanisms according to the present model. The upper branch describes autoregulation, the middle branch indicates $\mathrm{CO}_{2}$ response, and the lower branch describes $\mathrm{NO}$ reactivity. The input quantity for autoregulation is cerebral blood flow change $\left(\Delta \mathrm{CBF}=\frac{q-q_{n}}{q_{n}}\right)$. The input quantities for the $\mathrm{CO}_{2}$ and $\mathrm{NO}$ mechanisms are the logarithm of arterial $\mathrm{CO}_{2}$ tension $\left(P_{a \mathrm{CO}}\right)$, i.e. $\Delta P_{a \mathrm{CO}_{2}}=\log _{10}\left(P_{a \mathrm{CO}_{2}} / P_{a \mathrm{CO}_{2} n}\right)$, and the logarithm of $\mathrm{NO}$ production $\left(q_{\mathrm{NO}}\right)$, i.e. $\Delta q_{\mathrm{NO}}=\log _{10}\left(q_{\mathrm{NO}} / q_{\mathrm{NO} n}\right)$, respectively. The dynamics of these mechanisms are simulated by means of a gain factor $(G)$ and a first-order low-pass filter with time constant $\tau$. The variables $x_{\text {aut }}, x_{\mathrm{CO}_{2}}$ and $x_{\mathrm{NO}}$ are three state variables of the model that account for the effect of autoregulation, $\mathrm{CO}_{2}$ reactivity and NO reactivity, respectively, they are given in $\mathrm{ml} / \mathrm{mm} \mathrm{Hg} . q_{n}$, $P_{a \mathrm{CO}_{2} n}$ and $q_{\mathrm{NO} n}$ are set points for the regulatory mechanisms. The gain factor of the $\mathrm{CO}_{2}$ reactivity is multiplied by a corrective factor $A_{\mathrm{CO}_{2}}$, because as a consequence of tissue ischemia $\mathrm{CO}_{2}$ reactivity is depressed at low $\mathrm{CBF}$ levels. These three mechanisms interact nonlinearly through a sigmoidal static relationship, and therefore producing changes in pial arterial compliance and resistance.

For this regulation mechanism the following assumptions are made: first, only the impact of nitric oxide (NO) on the smooth muscle cells of pial vessels is considered, whereas the response of large arteries and veins on nitric oxide is neglected. Second, although there are distinct sources of $\mathrm{NO}$ in brain, e.g. neuronal or endothelial NO, the model does not differentiate the different sources of NO. Furthermore, no interactions of NO with other substances are considered.

In the case of a head injury production of nitric oxide occurs at the endothelial cells of the pial arteries and arterioles. These NO molecules migrate through the vessel wall to the smooth muscle cells and activate a substance called guanylcyclase there, which causes a higher production of guanosine $3^{\prime}, 5^{\prime}$-cyclic monophosphate (cGMP) with subsequent relaxation. In contrast any decrease in NO production causes constriction of the pial vessels.

The lower branch of figure 4 represents the NO reactivity, which is activated by changes in the NO production rate $q_{\mathrm{NO}}$ and described by a first-order lowpass filter dynamic with time constant $\tau_{\mathrm{NO}}$ and gain $G_{\mathrm{NO}}$

$$
\tau_{\mathrm{NO}} \frac{\mathrm{d} x_{\mathrm{NO}}}{\mathrm{d} t}=-x_{\mathrm{NO}}+G_{\mathrm{NO}} \log _{10}\left(\frac{q_{\mathrm{NO}}}{q_{\mathrm{NO} n}}\right)
$$

where $q_{\mathrm{NO} n}$ defines the NO production rate under basal conditions, corresponding to [10] it is $q_{\mathrm{NO} n}=54.1 \mathrm{ng} / \mathrm{g}$ tissue.

It is assumed that the production rate $q_{\mathrm{NO}}$ is linearly correlated with the concentration of nitric oxide $C_{\mathrm{NO}}$ in the vessel wall and that the vessel radius dependence on $\log _{10}$ of NO concentration is almost linear in the range of physiological conditions (cf. [11,12]). These are the reasons why the logarithm of $q_{\mathrm{NO}}$ is chosen as input to the controller. The regulation gain $G_{\mathrm{NO}}$ is then given by fitting the data of Wang et al. [13].
The time constants of these three regulation mechanisms $\tau_{\text {aut }}, \tau_{\mathrm{CO}_{2}}$ and $\tau_{\mathrm{NO}}$ are approximated by using data of references $[9,13,14]$, the values are 20,50 and $40 \mathrm{~s}$, respectively.

The minus sign at the upper branch of figure 4 means that an increase in cerebral blood flow causes vasoconstriction, with a decrease in pial compliance and an increase in pial resistance as consequence. Whereas, the plus signs at the middle and lower branches of figure 4 , mean that an increase in arterial $\mathrm{CO}_{2}$ pressure or in endothelial NO production causes vasodilation, with an increase in pial compliance and a decrease in pial resistance as consequence.

\subsection{Impact of the regulation mechanisms on $C_{\mathrm{pa}}$ and $R_{\mathrm{pa}}$ and their interactions}

According to [15], the impact of NO production at the endothelial cells on arterial $\mathrm{CO}_{2}$ pressure is very small. Therefore, only the effect of $P_{a \mathrm{CO}}$ on the production rate $q_{\mathrm{NO}}$ is considered in this model. According to [16], an $70 \%$ increase in arterial $\mathrm{CO}_{2}$ pressure yields an $20 \%$ increase in the $\mathrm{NO}$ production rate. It is assumed that these two mechanisms are connected linearly by the following equation

$$
q_{\mathrm{NO}}=0.4332 P_{a \mathrm{CO}_{2}}+39.8048 .
$$

Autoregulation is influenced by NO reactivity because of changes in CBF. The model considers this effect although these two mechanisms are not directly connected.

The three regulation mechanisms described above do not act linearly on the pial vessels. The first nonlinearity is given by the fact that the strength of $\mathrm{CO}_{2}$ reactivity is not independent of $\mathrm{CBF}$ level but decreases significantly during severe ischemia. Such a severe ischemia is associated with tissue acidosis, which buffers the effect 
of $\mathrm{CO}_{2}$ changes on perivascular $\mathrm{pH}$. This phenomenon is modelled by the corrective factor $A_{\mathrm{CO}_{2}}$

$$
A_{\mathrm{CO}_{2}}=\frac{1}{1+\exp \left\{\left[-k_{\mathrm{CO}_{2}}\left(q-q_{n}\right) / q_{n}\right]-b_{\mathrm{CO}_{2}}\right\}}
$$

with constant parameters $k_{\mathrm{CO}_{2}}$ and $b_{\mathrm{CO}_{2}}$ (cf. [2]).

Another nonlinearity is given by the fact that the whole regulation process is not just the sum of these three mechanisms but is described by a sigmoidal relationship with upper and lower saturation levels. Adapting the situation of Ursino et al. [2] to three regulation mechanisms one gets
The cerebrovascular control mechanisms act also on the hydraulic pial arterial resistance $R_{\mathrm{pa}}$. Because the blood volume is directly proportional to the inner radius second power, while the resistance is inversely proportional to inner radius forth power, the following relationship holds between the pial arterial volume and resistance (cf. [2])

$$
R_{\mathrm{pa}}=\frac{k_{\mathrm{R}} C_{\mathrm{pan}}^{2}}{V_{\mathrm{pa}}^{2}}
$$

where $k_{\mathrm{R}}$ is a constant parameter.

$$
C_{\mathrm{pa}}=\frac{\left(C_{\mathrm{pan}}-\Delta C_{\mathrm{pa}} / 2\right)+\left(C_{\mathrm{pan}}+\Delta C_{\mathrm{pa}} / 2\right) \cdot \exp \left[\left(x_{\mathrm{CO}_{2}}+x_{\mathrm{NO}}-x_{\mathrm{aut}}\right) / k_{C_{\mathrm{pa}}}\right]}{1+\exp \left[\left(x_{\mathrm{CO}_{2}}+x_{\mathrm{NO}}-x_{\mathrm{aut}}\right) / k_{C_{\mathrm{pa}}}\right]}
$$

where $C_{\text {pan }}$ is the pial arterial compliance under basal conditions, $\Delta C_{\mathrm{pa}}$ the change in compliance and $k_{C_{\mathrm{pa}}}$ a constant parameter.

This equation shows that any decrease in $\mathrm{CBF}$, any increase in arterial $\mathrm{CO}_{2}$ pressure and any increase in the $\mathrm{NO}$ production rate causes vasodilation with an increase in pial arterial compliance $C_{\text {pa }}$. On the other hand, any increase in $\mathrm{CBF}$, any decrease in arterial $\mathrm{CO}_{2}$ pressure and any decrease in NO production rate causes vasoconstriction with a reduction in compliance $C_{\mathrm{pa}}$

A value for the constant parameter $k_{C_{\mathrm{pa}}}$ was given to set the central slope of the sigmoidal curve to +1 . This condition is obtained by assuming $k_{C_{\mathrm{pa}}}=\Delta C_{\mathrm{pa}} / 4$.

An important point is that this sigmoidal curve is not symmetrical: the increase in blood volume caused by vasodilation is greater than the decrease of blood volume caused by vasoconstriction. That is the reason why two different values of the parameter $\Delta C_{\mathrm{pa}}$ have to be chosen depending on whether vasodilation or vasoconstriction is considered. It is

$$
\left\{\begin{array}{l}
x_{\mathrm{CO}_{2}}+x_{\mathrm{NO}}-x_{\mathrm{aut}}>0: \Delta C_{\mathrm{pa}}=\Delta C_{\mathrm{pa} 1} ; k_{C_{\mathrm{pa}}}=\Delta C_{\mathrm{pa} 1} / 4 \\
x_{\mathrm{CO}_{2}}+x_{\mathrm{NO}}-x_{\mathrm{aut}}<0: \Delta C_{\mathrm{pa}}=\Delta C_{\mathrm{pa} 2} ; k_{C_{\mathrm{pa}}}=\Delta C_{\mathrm{pa} 2} / 4
\end{array}\right.
$$

Consider equation (29): For $\left(x_{\mathrm{CO}_{2}}+x_{\mathrm{NO}}-x_{\mathrm{aut}}\right) \rightarrow \infty$ one gets $C_{\mathrm{pa}} \rightarrow\left(C_{\mathrm{pan}}+\Delta C_{\mathrm{pal}} / 2\right)$ and $\left(x_{\mathrm{CO}_{2}}+x_{\mathrm{NO}}-\right.$ $\left.x_{\text {aut }}\right) \rightarrow-\infty$ yields $C_{\mathrm{pa}} \rightarrow\left(C_{\mathrm{pan}}-\Delta C_{\mathrm{pa} 2} / 2\right)$. That means $\left(C_{\mathrm{pan}}+\Delta C_{\mathrm{pa} 1} / 2\right)$ and $\left(C_{\mathrm{pan}}-\Delta C_{\mathrm{pa} 2} / 2\right)$ are the upper and lower saturation levels of the sigmoidal curve, respectively.

An expression for $\mathrm{d} C_{\mathrm{pa}} / \mathrm{d} t$ is obtained by differentiating equation (29) to

$$
\begin{aligned}
\frac{\mathrm{d} C_{\mathrm{pa}}}{\mathrm{d} t}= & \frac{\Delta C_{\mathrm{pa}}}{k_{C_{\mathrm{pa}}}} \cdot \frac{\exp \left[\left(x_{\mathrm{CO}_{2}}+x_{\mathrm{NO}}-x_{\mathrm{aut}}\right) / k_{C_{\mathrm{pa}}}\right]}{\left\{1+\exp \left[\left(x_{\mathrm{CO}_{2}}+x_{\mathrm{NO}}-x_{\mathrm{aut}}\right) / k_{C_{\mathrm{pa}}}\right]\right\}^{2}} \\
& \times \frac{\mathrm{d}\left(x_{\mathrm{CO}_{2}}+x_{\mathrm{NO}}-x_{\mathrm{aut}}\right)}{\mathrm{d} t} .
\end{aligned}
$$

\subsection{Norepinephrine and its impact on heart rate}

Norepinephrine is the principal mediator of the sympathetic nervous system. Cardiac function is modulated in many aspects by norepinephrine. The primary effect of this substance is an increase in heart rate and thus an increase in cardiac output $Q$ (figure 5).

The changes of the norepinephrine concentration in blood $\mathrm{d}[\mathrm{NE}] / \mathrm{d} t$ are described by the equation

$$
\frac{\mathrm{d}[\mathrm{NE}]}{\mathrm{d} t}=r-\alpha_{\mathrm{NE}}[\mathrm{NE}],
$$

where $r$ is the constant NE release during sympathetic nerve stimulation and $\alpha_{\mathrm{NE}}$ is the elimination rate.

Because absolute values of [NE] are unknown $r$ can be fixed to one in the case of sympathetic nerve activation without loss of generality, otherwise $r$ is chosen as zero. That means this mechanism of NE release is switched on and off by the parameter $r$ and the parameter $\alpha_{\mathrm{NE}}$ specifies the strength of sympathetic nerve stimulation and can be varied throughout the simulations.

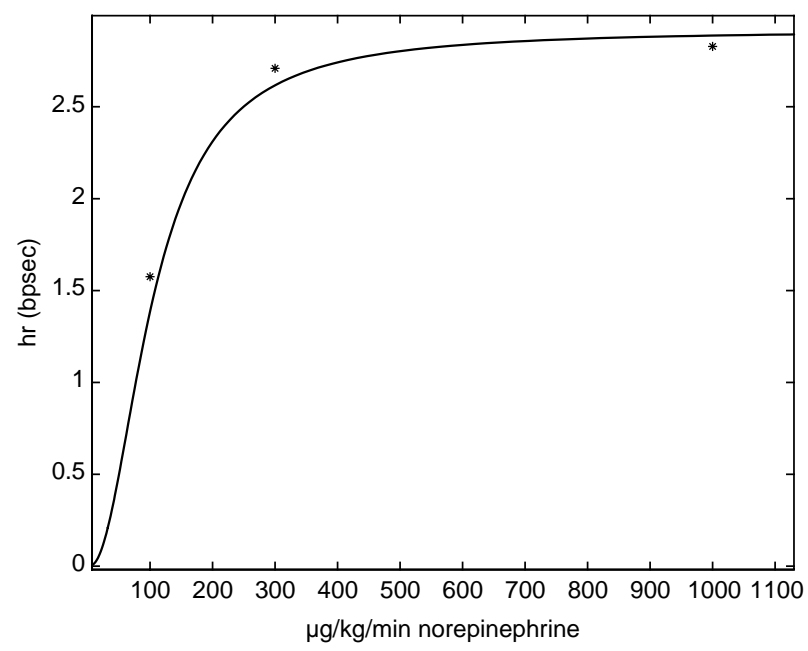

Figure 5. Dependence of heart rate variation $\mathrm{hr}$ on the amount of norepinephrine in blood. Model results (solid curve) and measured data of Muchitsch et al. ([17]). 
The heart rate response to a steplike increase of the norepinephrine concentration [NE] is described by a firstorder low-pass filter dynamic with time constant $\tau_{\mathrm{hr}}$

$$
\tau_{\mathrm{hr}} \frac{\mathrm{dhr}}{\mathrm{d} t}=-\mathrm{hr}+G([\mathrm{NE}])
$$

where hr is the heart rate variation. The steady-state heart rate response $G([\mathrm{NE}])$ is, according to [18], defined by

$$
\Delta \mathrm{HR}=G([\mathrm{NE}])=\frac{\Delta \mathrm{HR}_{\max }[\mathrm{NE}]^{2}}{k_{\mathrm{NE}}^{2}+[\mathrm{NE}]^{2}}
$$

where $K_{\mathrm{NE}}$ is the NE concentration producing a half maximum response and $\Delta \mathrm{HR}_{\max }$ is the maximum value of $\Delta$ HR. Corresponding to Muchitsch et al. [17], the values of these parameters are $175 \mathrm{bpm}$ and $100 \mu \mathrm{g} \mathrm{kg}^{-1} \mathrm{~min}$, respectively and the time constant $\tau_{\mathrm{hr}}$ is $5 \mathrm{~s}$.

The new heart rate $\bar{b}$ is then given by adding the heart rate variation hr to $b$

$$
\bar{b}=b+\mathrm{hr} .
$$

\section{Parameter estimation}

The estimation of systemic parameters under basal conditions is described now. The values of the compliances in the craniospinal space, like $C_{\mathrm{la}}, C_{\mathrm{pa}}$ and $C_{\mathrm{vi}}$, and the intracranial compliance $C_{\mathrm{ic}}$ were fitted by using pressure curves of these compartments. The values were fitted in the way that the model amplitudes of the pressures in each compartment are equal to the given physiological amplitudes of pressures (cf. [19-22]).

The basal value of the resistance of the large intracranial arteries is calculated by using the Hagen-Poiseuille law $R=(8 \eta l) /\left(r^{4} \pi\right)$. All other model resistances, $R_{\mathrm{s}}, R_{\mathrm{pa}}, R_{\mathrm{pv}}$, $R_{\mathrm{vs}}$ and $R_{\mathrm{ve}}$ are calculated by using the mean pressure values in each compartment (see [19-21]) and solving the differential equations defined above. All model parameters under basal conditions are given in table 1 .

\begin{tabular}{|c|c|}
\hline $\begin{array}{l}C_{\mathrm{a}}=0.0042 \mathrm{ml} / \mathrm{mm} \mathrm{Hg} \\
n=13 \\
\nu=0.1852 \mathrm{ml} \text { per beat } \\
R_{\mathrm{la}}=47.1609 \mathrm{~mm} \mathrm{Hg} \cdot \mathrm{s} \cdot \mathrm{ml}^{-1}\end{array}$ & $\begin{array}{l}R_{\mathrm{S}}=99.4286 \mathrm{~mm} \mathrm{Hg} \cdot \mathrm{s} \cdot \mathrm{ml}^{-1} \\
B=378 / 60 \text { beats per second } \\
k_{\text {Cla }}=0.0305 \mathrm{ml} \\
k_{\mathrm{R}}=1.6258 e+06 \mathrm{~mm} \\
\mathrm{Hg}^{3} \cdot \mathrm{s} \cdot \mathrm{ml}^{-1}\end{array}$ \\
\hline $\begin{array}{l}C_{\mathrm{pan}}=4.7277 e-07 \mathrm{ml} / \mathrm{mm} \mathrm{Hg} \\
\Delta C_{\mathrm{pa} 2}=3.7822 e-07 \mathrm{ml} / \mathrm{mm} \mathrm{Hg} \\
R_{f}=2830 \mathrm{~mm} \mathrm{Hg} \cdot \mathrm{s} \cdot \mathrm{ml}^{-1}\end{array}$ & $\begin{array}{l}\Delta C_{\mathrm{pa} 1}=6.6188 e-06 \mathrm{ml} / \mathrm{mm} \mathrm{Hg}^{-1} \\
R_{\mathrm{pv}}=29.4756 \mathrm{~mm} \mathrm{Hg} \cdot \mathrm{s} \cdot \mathrm{ml}^{-1} \\
R_{\mathrm{o}}=1783 \mathrm{~mm} \mathrm{Hg} \cdot \mathrm{s} \cdot \mathrm{ml}^{-1}\end{array}$ \\
\hline$q_{n}=0.1696 \mathrm{ml} \cdot \mathrm{s}^{-1}$ & $\tau_{\text {aut }}=20 \mathrm{~s}$ \\
\hline$G_{\text {aut }}=0.00006$ & $\tau_{\mathrm{CO}_{2}}=50 \mathrm{~s}$ \\
\hline$G_{\mathrm{CO}_{2}}=0.000435$ & $P_{a_{C O} n}=33 \mathrm{~mm} \mathrm{Hg}$ \\
\hline$\tau_{\mathrm{NO}}=40 \mathrm{~s}$ & $G_{\mathrm{NO}}=0.000125$ \\
\hline$q_{N O n}=54.1 \mathrm{ng} / \mathrm{g}$ tissue & $k_{\mathrm{CO}_{2}}=27$ \\
\hline & $k_{\mathrm{ven}}=4.9353 \mathrm{e}-08 \mathrm{ml}$ \\
\hline$P_{\mathrm{cv}}=1.7 \mathrm{~mm} \mathrm{Hg}$ & $R_{\mathrm{vs} 1}=5.566 \mathrm{~mm} \mathrm{Hg} \cdot \mathrm{s} \cdot \mathrm{ml}^{-1}$ \\
\hline$P_{v 1}=-2.5 \mathrm{~mm} \mathrm{Hg}$ & $R_{\mathrm{ve}}=2.9476 \mathrm{~mm} \mathrm{Hg} \cdot \mathrm{s} \cdot \mathrm{ml}^{-1}$ \\
\hline$k_{E}=41 \mathrm{~m}$ & $D_{\max }=175 / 60$ beats per second \\
\hline$\tau_{\mathrm{hr}}=5 \mathrm{~s}$ & $k_{\mathrm{NE}}=100 \mu \mathrm{g} \cdot \mathrm{kg}^{-1} \cdot \min$ \\
\hline
\end{tabular}

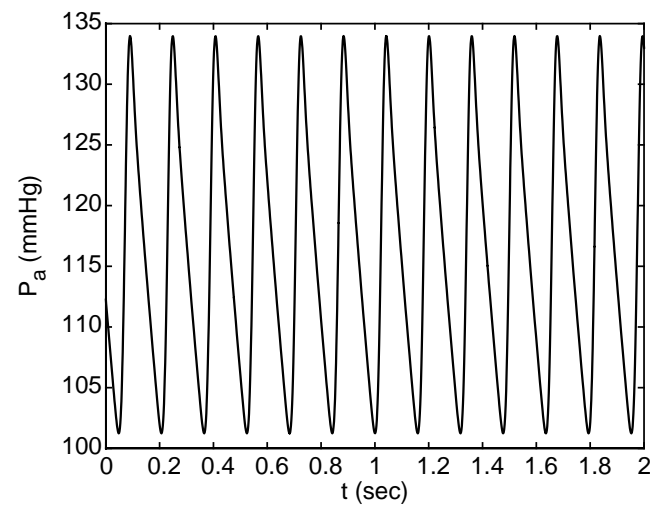

Table 1. Basal values of model parameters.

\section{Numerical simulations}

With the parameters given in table 1 numerical simulations were performed to show that the model gives a reasonable and realistic description of the physiologic system.

Figure 6 shows the simulated pressure in the aorta $P_{\mathrm{a}}$ and the intracranial pressure $P_{\mathrm{ic}}$. These pressures agree with experimental data of Baumbach [20], who measured a systolic blood pressure of $134 \pm 7 \mathrm{~mm} \mathrm{Hg}$ and a diastolic pressure of $98 \pm 6 \mathrm{~mm} \mathrm{Hg}$ and with data of Holtzer et al. [22] who measured a mean intracranial pressure of $6 \pm 3 \mathrm{~mm} \mathrm{Hg}$ and an amplitude of the pressure curve of approximately $1.4 \mathrm{~mm} \mathrm{Hg}$.

The simulated pressure of the small arteries and arterioles in the left of figure 7 agrees with the measured data of $67 \pm 4 \mathrm{~mm} \mathrm{Hg}$ for the pial systolic pressure and $53 \pm 3 \mathrm{~mm} \mathrm{Hg}$ for the pial diastolic pressure by Baumbach [20]. Further on, the works of Gotoh et al. [19] and Sugiyama et al. [21] suggest a mean large cerebral arteries pressure of $108 \mathrm{~mm} \mathrm{Hg}$ and an amplitude of $23 \mathrm{~mm} \mathrm{Hg}$, which agrees also with the simulated pressure curve in the right hand side part of the figure.

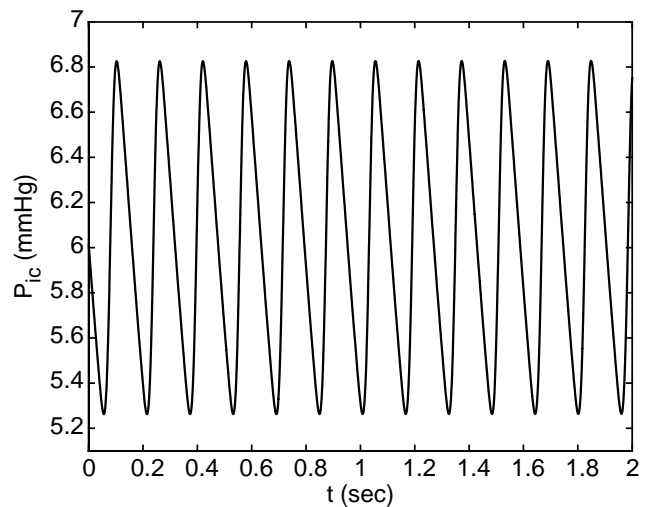

Figure 6. Left: simulated blood pressure in the aorta, received by solving equation (2). Right: simulated intracranial pressure curve, received by solving equation (11). 

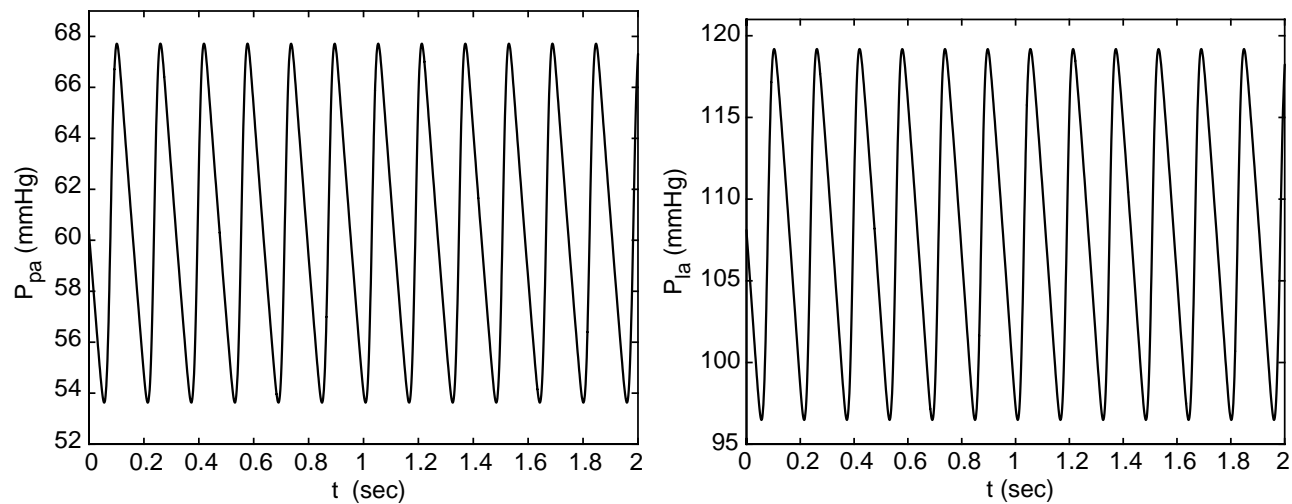

Figure 7. Left: simulated pressure curve of the pial arteries, received by solving equation (16). Right: simulated pressure curve of the large arteries, received by solving equation (14).

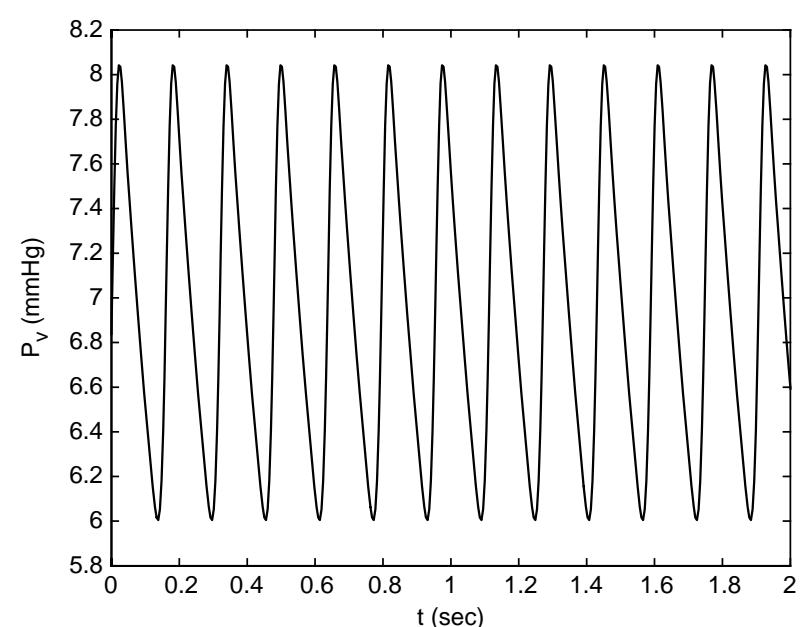

Figure 8. Simulated pressure curve of the cerebral veins, received by solving equation (18).

Figure 8 shows the simulated pressure of the cerebral veins $P_{\mathrm{v}}$. A mean cerebral venous pressure of $7 \pm 1 \mathrm{~mm} \mathrm{Hg}$ is given by Mayhan and Heistad [23].

The simulated dependence of cerebral blood flow on arterial $\mathrm{CO}_{2}$ pressure is shown in the left hand side part of the figure 9 . One observes a $230 \%$ increase in cerebral blood flow, if $P_{a \mathrm{CO}_{2}}$ is changed from 34.3 to $49.2 \mathrm{~mm} \mathrm{Hg}$. This result corresponds to the measured data of Iadecola et al. [9]. Further on, the impact of $\mathrm{NO}$ on $\mathrm{CBF}$ is simulated and the result is given in the right of figure 9 .

To show that the interaction between $\mathrm{CO}_{2}$ and $\mathrm{NO}$ reactivity is modelled realistically, the dependence of $P_{a \mathrm{CO}_{2}}$ on $\mathrm{NO}$ is simulated by calculating the $\mathrm{CO}_{2}$ reactivity with the basal value of $q_{\mathrm{NO}}$ and with inhibition of $\mathrm{NO}$ production. The results are shown in figure 10: the solid curve is equal to the left curve in figure 9 , since $q_{\mathrm{NO}}=q_{\mathrm{NO} n}$ and the dashed curve is the simulation result with inhibited NO production, $q_{\mathrm{NO}}=0.1 \cdot q_{\mathrm{NO} n}$. The resulting decrease in CBF corresponds to the data of Wang et al. [13].

In addition to the numerical simulations described above, the impact of the sympathetic system, i.e. norepinephrine on heart rate and cardiac output, is simulated. The strength of sympathetic nerve stimulation is regulated by the parameter $\alpha_{\mathrm{NE}}$. Choosing a value of $\alpha_{\mathrm{NE}}=0.04$ corresponds to a stimulation with a frequency of $2 \mathrm{~Hz}$ and yields a release of norepinephrine like the one measured by Mokrane et al. [18]. Figure 11 shows the simulated increase of $[\mathrm{NE}]$ and the corresponding simulated hr response. Any increase in heart rate yields
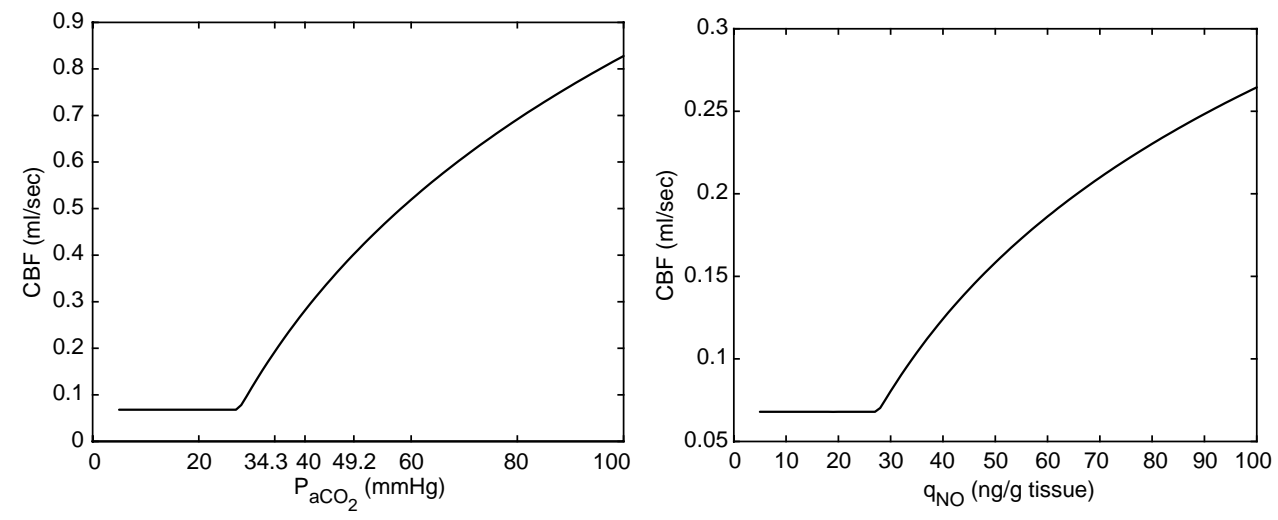

Figure 9. Left: dependence of $\mathrm{CBF}$ on arterial $\mathrm{CO}_{2}$ pressure simulated by the model. Iadecola et al. [9] measured, by increasing $P_{a \mathrm{CO}_{2}}$ from 34.3 to $49.2 \mathrm{~mm} \mathrm{Hg}$, an increase in cerebral blood flow of $230 \%$. Right: the effect of changes in the NO production rate $q_{\mathrm{NO}}$ on cerebral blood flow is simulated by the model. The basal value of $\mathrm{CBF}\left(q_{n}=0.1696 \mathrm{ml} \mathrm{s}^{-1}\right)$ is given by a production rate of $q_{\mathrm{NO}}=54.1 \mathrm{ng} / \mathrm{g}$ tissue. 


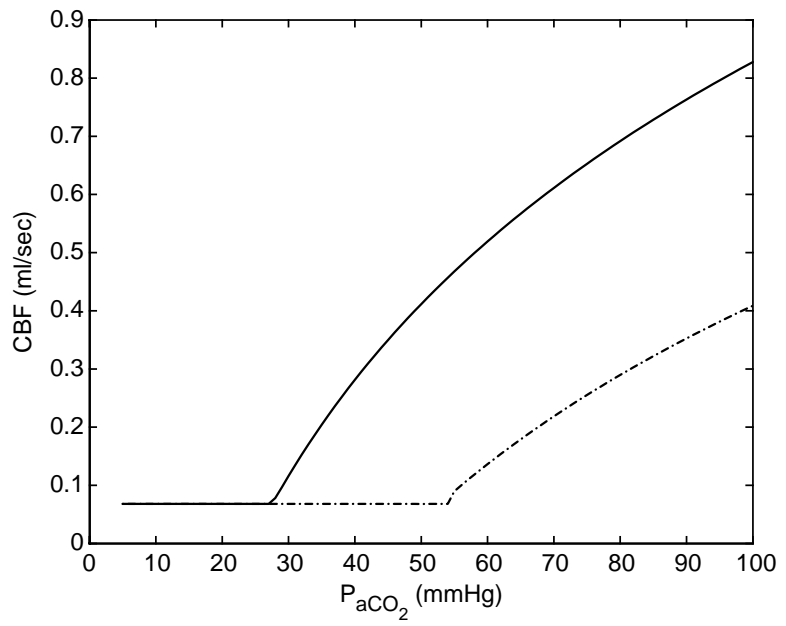

Figure 10. The dependence of $\mathrm{CO}_{2}$ reactivity on $\mathrm{NO}$ is simulated by the model. The solid curve shows the dependence of $\mathrm{CBF}$ on $P_{a \mathrm{CO}_{2}}$, here the linear relationship between $\mathrm{NO}$ production and $\mathrm{CO}_{2}$ pressure (equation (27)) was used (see, figure 9). The dashed curve is the result of a model simulation with inhibition of $\mathrm{NO}$ production, $q_{\mathrm{NO}}=0.1 q_{\mathrm{NO} n}$ (corresponding to Wang et al. [13]).

an increase in cardiac output $Q$ (see equation (6)) and thus an increase in blood pressure $P_{\mathrm{a}}$ (see equation (2)). The impact of changes in heart rate on these cardiac parameters are simulated and the results are shown in figure 12. The mean value of cardiac output $Q$ is used for simulations to show the increase in this variable and in blood pressure $P_{\mathrm{a}}$ more clearly.

\section{Validation}

For the validation of the model, experimental data of [24-29] were used as reference examples and compared to numerical simulations. These experimental results reflect special physiological situations and were not used to calibrate the model parameters.

The numerically simulated $\mathrm{CO}_{2}$ reactivities for different values of mean arterial blood pressure and intracranial pressure are shown in figure 13. The top left of figure 13 shows the dependence of $\mathrm{CBF}$ under intracranial normotension $\left(P_{\mathrm{ic}}=4 \mathrm{~mm} \mathrm{Hg}\right)$ and different values of MAP: $A_{1}-P_{\mathrm{a}}=97 \mathrm{~mm} \mathrm{Hg}, A_{2}-P_{\mathrm{a}}=77 \mathrm{~mm} \mathrm{Hg}$, and $A_{3}-P_{\mathrm{a}}=64 \mathrm{~mm} \mathrm{Hg}$. Decreasing the mean arterial blood pressure provides a decreased $\mathrm{CBF}$ for increased values of $P_{a \mathrm{CO}_{2}}$. Hauerberg et al. [24] measured the dependence of cerebral blood flow on $P_{a \mathrm{CO}_{2}}$ for the above given intracranial and blood pressure values. They also got a qualitative decreased $\mathrm{CBF}$ for decreased arterial and increased $\mathrm{CO}_{2}$ pressure values.

The top right of figure 13 shows the dependence of cerebral blood flow on arterial $\mathrm{CO}_{2}$ pressure under intracranial hypertension $\left(P_{\text {ic }}=31 \mathrm{~mm} \mathrm{Hg}\right)$ and $B_{1}$ $P_{\mathrm{a}}=104 \mathrm{~mm} \mathrm{Hg}, B_{2}-P_{\mathrm{a}}=123 \mathrm{~mm} \mathrm{Hg}$. Increasing the mean arterial blood pressure yields an increase in CBF for higher values of $P_{a \mathrm{CO}_{2}}$. This change in $\mathrm{CBF}$ was also measured by Hauerberg et al. [24] and they stated that the groups $A_{1}$ and $B_{2}$ are similar.

The bottom of figure 13 shows the $\mathrm{CO}_{2}$ reactivity for a further increased intracranial pressure of $50 \mathrm{~mm} \mathrm{Hg}$ and for $C_{1}-P_{\mathrm{a}}=104 \mathrm{~mm} \mathrm{Hg}$ and $C_{2}-P_{\mathrm{a}}=123 \mathrm{~mm} \mathrm{Hg}$. Increasing the mean arterial blood pressure yields an increase in $\mathrm{CBF}$ for higher values of $P_{a \mathrm{CO}_{2}}$ as can be seen in Hauerberg et al. [24], who also stated the similarity of the groups $A_{2}, B_{1}$ and $C_{2}$.

In figure 14 a simulated autoregulation curve is shown. For validation of the lower autoregulation limit, which lies in the range of 40 and $55 \mathrm{~mm} \mathrm{Hg}$, a work of Waschke et al. [25] is used. Corresponding to their experimental studies the mean arterial blood pressure is decreased from 116 to $86,70,55$ and $40 \mathrm{~mm} \mathrm{Hg}$ and the mean cerebral blood flow is calculated for the given pressure values by the model. In figure 15 the experimental results of Waschke et al. [25] are shown and compared with the simulated data. A significant decrease in cerebral blood flow, if blood pressure is decreased from 55 to $40 \mathrm{~mm} \mathrm{Hg}$, can be seen in the measured data as well as in the simulated data.

For validation of the upper autoregulation limit, which lies in the range of 150 and $160 \mathrm{~mm} \mathrm{Hg}$, a work of Schaller et al. [26] is used. The data of their control group of the
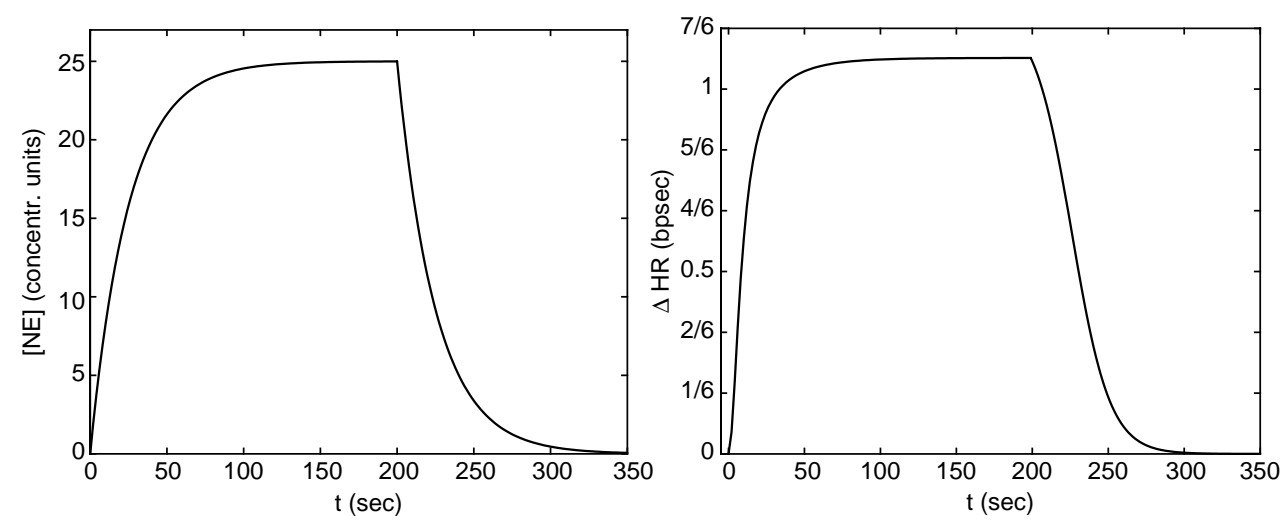

Figure 11. Left: simulated increase of [NE] with a stimulation domain of 0-200 s. Right: simulated heart rate response corresponding to these changes in $[\mathrm{NE}]$. 

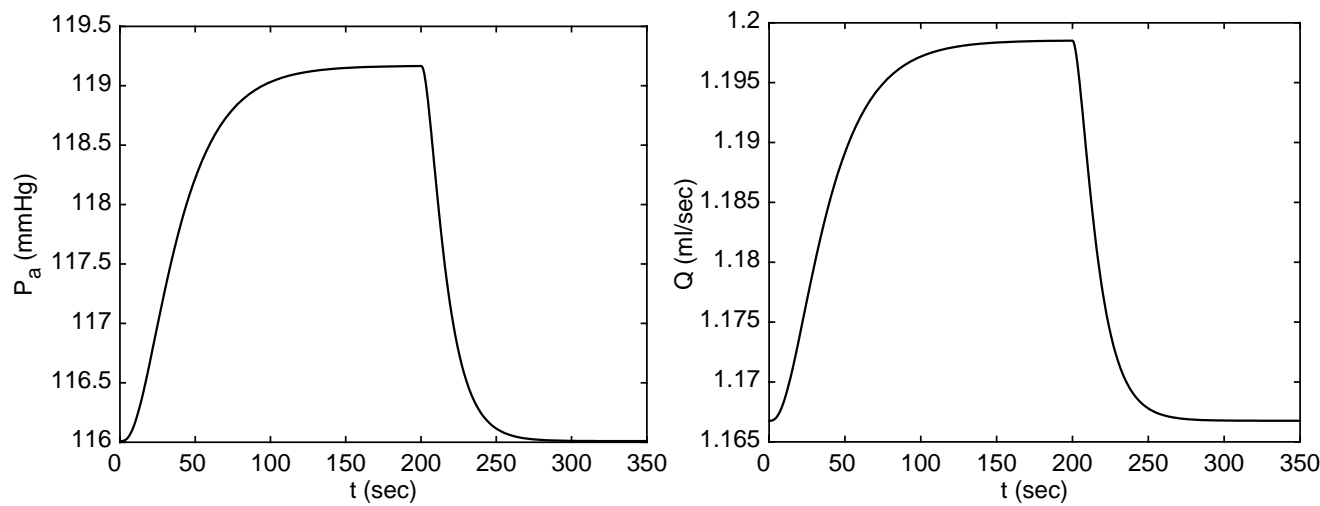

Figure 12. Left: simulated increase in blood pressure $P_{\mathrm{a}}$. Right: simulated cardiac output response, to a stimulation interval of $0-200 \mathrm{~s}$ and with a stimulation intensity of $\alpha_{\mathrm{NE}}=0.04$.

investigated Wistar rats is compared with simulation results in figure 16, where mean arterial pressure is increased up to 10, 20, 30, 40 and 50 percent of its basal value and the corresponding cerebral blood flow is measured and calculated, respectively. One can see the increase in cerebral blood flow if blood pressure is increased up to $40-50 \%$ of its basal value in the measured data as well as in the simulated data.
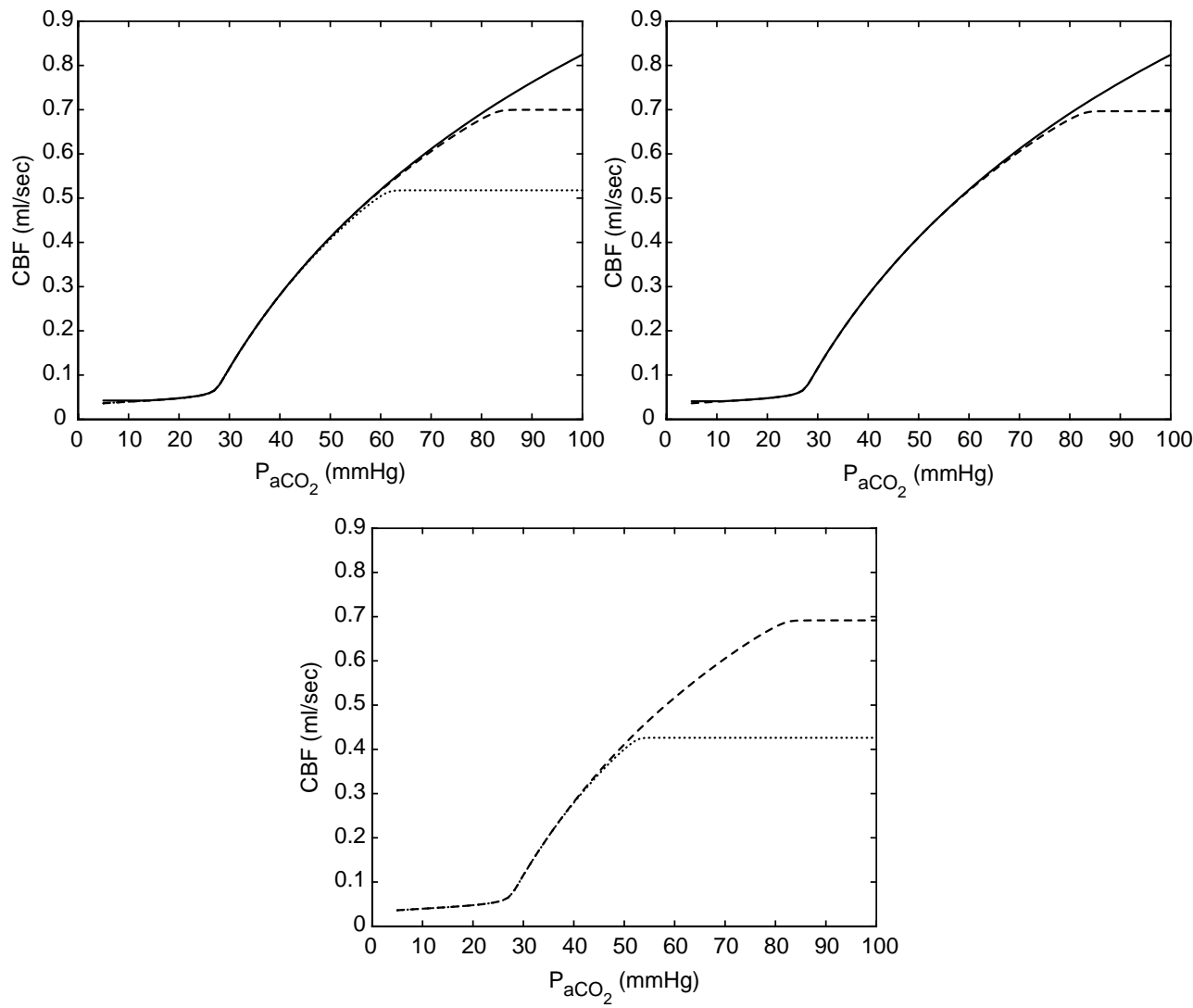

Figure 13. Top left: simulated dependence of CBF on $P_{a \mathrm{CO}_{2}}$ for $P_{\mathrm{ic}}=4 \mathrm{~mm} \mathrm{Hg}$ and $A_{1}-P_{\mathrm{a}}=97 \mathrm{~mm} \mathrm{Hg}$, solid line, $A_{2}-P_{\mathrm{a}}=77 \mathrm{~mm} \mathrm{Hg}$, dashed line and $A_{3}-P_{\mathrm{a}}=64 \mathrm{~mm} \mathrm{Hg}$, dotted line. Decreasing MAP under intracranial normotension results in a decrease in CBF for increased values of $P_{a \mathrm{CO}_{2}}$ (cf. [24]). Top right: simulated dependence of $\mathrm{CBF}$ on $P_{a \mathrm{CO}_{2}}$ for $P_{\mathrm{ic}}=31 \mathrm{~mm} \mathrm{Hg}$ and $B_{1}-P_{\mathrm{a}}=104 \mathrm{~mm} \mathrm{Hg}$, dashed line, $B_{2}-P_{\mathrm{a}}=123 \mathrm{~mm} \mathrm{Hg}$, solid line. Increasing MAP yields an increase in CBF for higher values of $P_{a \mathrm{CO}_{2}}$. The simulation results of $B_{2}$ and $A_{1}$ are similar. These phenomenons were also measured by Hauerberg et al. [24]. Bottom: simulated $\mathrm{CO}_{2}$ reactivity for $P_{\mathrm{ic}}=50 \mathrm{~mm} \mathrm{Hg}$ and $C_{1}-P_{\mathrm{a}}=104 \mathrm{~mm} \mathrm{Hg}$, dotted line, and $C_{2}: P_{\mathrm{a}}=$ $123 \mathrm{~mm} \mathrm{Hg}$, dashed line. Increasing MAP yields an increase in CBF for higher values of $P_{a \mathrm{CO}_{2}}$. The simulation results of $C_{2}, A_{2}$ and $B_{1}$ are similar. These phenomenons were also measured by Hauerberg et al. [24]. 


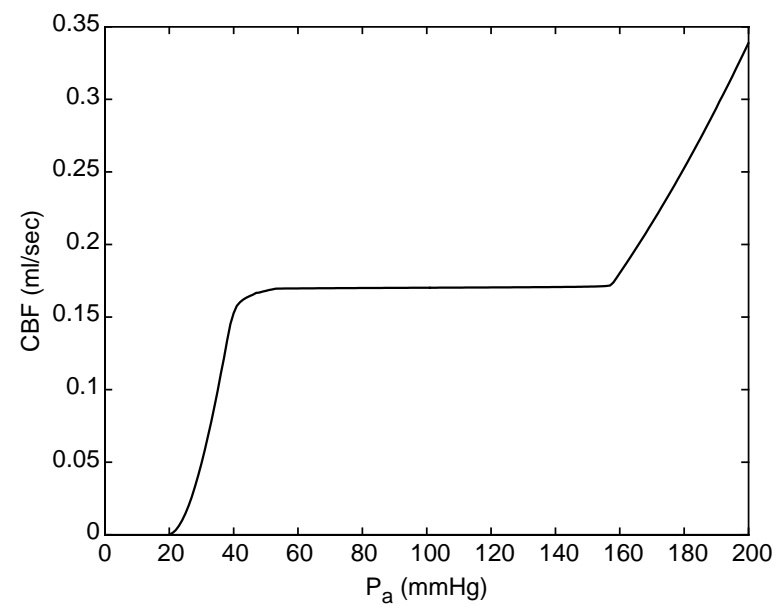

Figure 14. Autoregulation curve simulated by the model. The lower autoregulation limit lies, corresponding to Waschke et al. [25], in the range of 40 and $55 \mathrm{~mm} \mathrm{Hg}$, the upper regulation limit was not investigated in their work. Corresponding to Schaller et al. [26] loss of autoregulation with increase in $\mathrm{CBF}$ occurred at approximately $P_{\mathrm{a}}=150$ $\mathrm{mm} \mathrm{Hg}$.

simulated with the given data of Waschke et al. [25]. The mean arterial blood pressure $P_{\mathrm{a}}$ was decreased linearly to $86,70,55$ and $40 \mathrm{~mm} \mathrm{Hg}$ and the cerebral blood flow under these conditions was calculated after another period of $1 \mathrm{~h} 25 \mathrm{~min}$.

Figure 17 shows the dependence of cerebral blood flow on mean arterial blood pressure in the situation of brain damage described above. The calculated lower autoregulation limit increased from $40<x<55 \mathrm{~mm} \mathrm{Hg}$ under basal conditions to $70<x<86 \mathrm{~mm} \mathrm{Hg}$. Engelborghs et al. [28] measured a lower autoregulation limit of $46.9 \pm 12.7$ in sham rats and $62.2 \pm 20.8$ in CHI rats.

In figure 18 the effect of L-NAME infusion on blood flow in the rat cerebral cortex is shown. Hudetz et al. [29] measured the laser-Doppler flow (LDF) thirty minutes after $\mathrm{N}^{\omega}$-nitro-L-arginine methyl esther (L-NAME) administration $(20 \mathrm{mg} / \mathrm{kg})$. LDF was reduced from $159 \pm 14$ to $135 \pm 11$ perfusion units (PU) (15\% decrease), whereas mean arterial pressure $\mathrm{Pa}$ was increased from $105 \pm 4$ to $132 \pm 6 \mathrm{~mm} \mathrm{Hg}$ (26\% increase).

This effect of nitric oxide inhibition is numerically simulated in the way that the following parameters are changed linearly in thirty minutes: the basal value of blood pressure $P_{\mathrm{a}}=116 \mathrm{~mm} \mathrm{Hg}$ is increased to $146.16 \mathrm{~mm} \mathrm{Hg}$ ( $26 \%$ increase) and the basal NO production rate $q_{\mathrm{NO}}=$ $54.1 \mathrm{ng} / \mathrm{g}$ tissue is decreased to $5.4 \mathrm{ng} / \mathrm{g}$ tissue $(90 \%$ decrease). The cerebral blood flow was calculated after another period of thirty minutes and it was decreased from 0.1696 to $0.1393 \mathrm{ml} \mathrm{s}^{-1}$ (17.8\% decrease).

\section{Discussion}

In this paper, a mathematical model is presented which describes cerebral hemodynamics under physiological aspects. The overall aim is to develop a tool that provides a more complete insight into the mechanisms of cerebrovascular perfusion with special emphasis of the interaction of different regulatory mechanisms. To facilitate hypothesis testing in the lab a species specific model using data from the Sprague-Dawley rat was developed. In the first instance, only two of the most robust mechanisms have been integrated into the model: $\mathrm{CO}_{2^{-}}$and NO-regulation.

By introducing a cardiac output function as input for the systemic blood circulation the blood pressure gets dependent on time and thus all pressures of the model and the blood flow become pulsatile. The implementation of pulsatile blood flow allows to investigate the effects of cardiac dysrhythmias on cerebral perfusion which is an important problem with respect to the increasing population of elderly trauma victims with cardiac comorbidities. The systemic circulation is closed for the first time in this model, so all changes in cardiac output result in changes of other systemic pressures and flows.

Maintenance of an adequate cerebral perfusion pressure is a mainstay of TBI (traumatic brain injury)
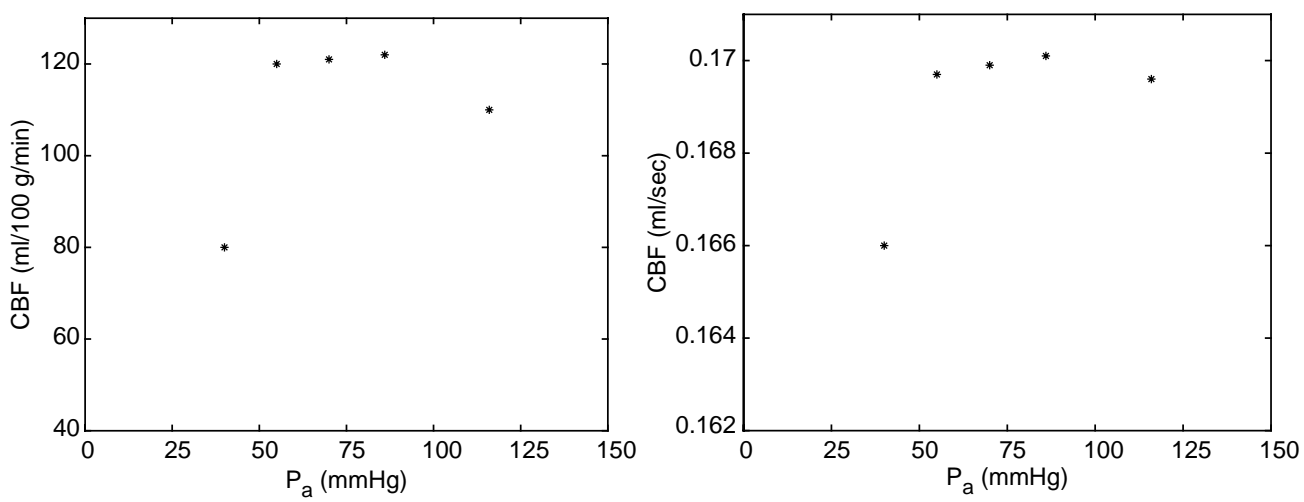

Figure 15. Left: measured data of Waschke et al. [25]: the mean arterial blood pressure $P_{\mathrm{a}}$ is reduced from 116 to $86,70,55$ and $40 \mathrm{~mm} \mathrm{Hg}$ and the mean cerebral blood flow is measured for the corresponding pressure values in $\mathrm{ml} / 100 \mathrm{~g} / \mathrm{min}$. Right: calculated mean cerebral blood flow for the given blood pressure values by the model. The changes in CBF depending on changes in blood pressure are qualitatively the same and it can be seen that the lower autoregulation limit must be in the range of 40 and $55 \mathrm{~mm} \mathrm{Hg}$. 

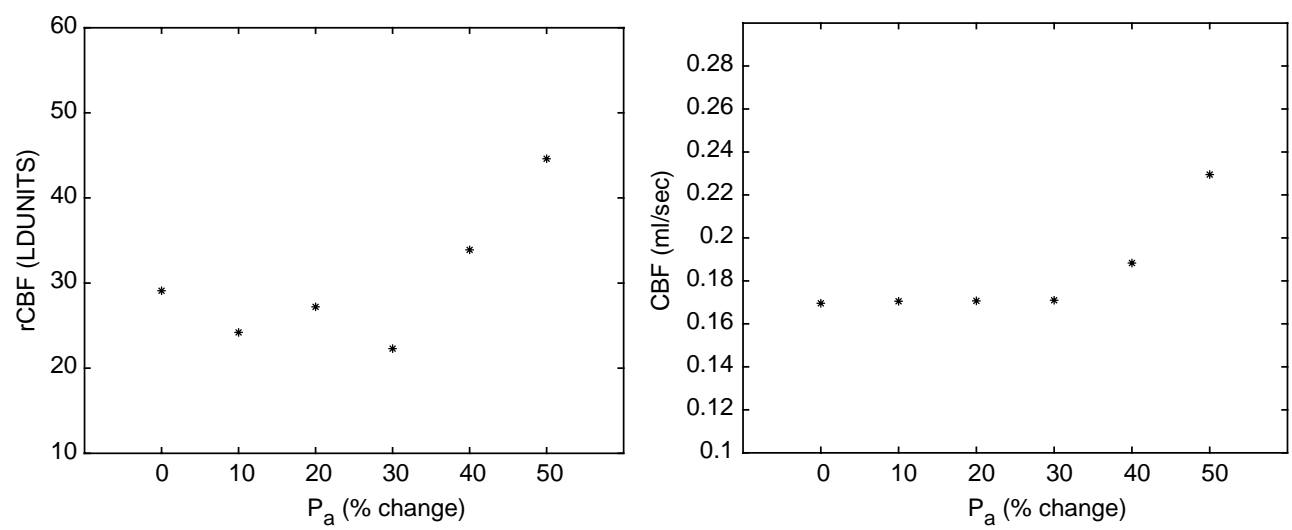

Figure 16. Left: measured data of Schaller et al. [26]: The mean arterial blood pressure $P_{\mathrm{a}}$ is raised up to 10,20,30,40 and 50 percent of its basal value $(116 \mathrm{~mm} \mathrm{Hg})$ and the mean regional cerebral blood flow is measured for the corresponding pressure values in LD-Units. Right: calculated mean cerebral blood flow for the given blood pressure values by the model. The increase in cerebral blood flow if blood pressure is increased up to 40 and $50 \%$ of its basal value is qualitatively the same and therefore the upper regulation limit must be in the range of 150 and $160 \mathrm{~mm} \mathrm{Hg}$.

therapy and is thought to be a necessary and potentially neuroprotective therapeutic intervention that "may be associated with a substantial reduction in mortality and improvement in quality of survival and is likely to enhance perfusion to ischemic regions of the brain after severe TBI" (cf. [30]). This goal can be reached by intravenous application of vasopressors (e.g. norepinephrine). The immediate effector organ of vasopressors is the heart where an increase of cardiac output results from modulation of heart rate and contractility. Interestingly there appears to be a feedback from TBI to cardio-circulatory performance in terms of a reduced response to vasopressors under certain conditions (cf. [22]). Thus, the system of sympathetic regulation of heart function needs to be implemented into a physiologically relevant model of cerebral perfusion. In the present version of the model only the very basic

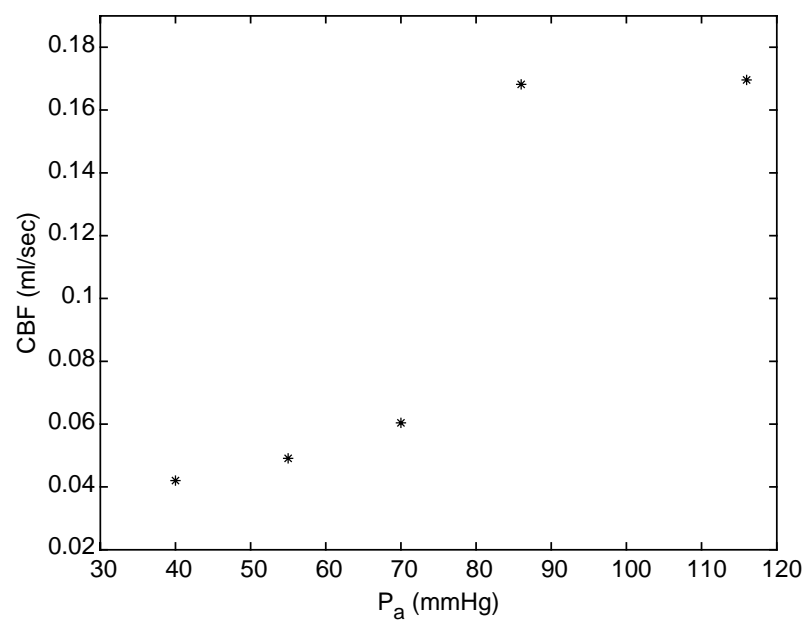

Figure 17. Numerically simulated dependence of CBF on mean arterial pressure under the situation of a head injury. The values of the intracranial pressure, $P_{a \mathrm{CO}_{2}}$ and $b$ under this condition are given by [27] and [25], respectively. The lower autoregulation limit increased and lies in the range of $70<x<86 \mathrm{~mm} \mathrm{Hg}$. mechanism of norepinephrine physiology was considered as the model is focused only on the most basic and robust mechanisms of cerebral perfusion (flow, autoregulation). After the fundamental behaviour of cerebral blood flow has been successfully modelled future versions of the model need to map the effects of vasopressors more precisely.

Other important features of the model are the regulation mechanisms, like autoregulation, $\mathrm{CO}_{2}=$ reactivity and NO reactivity, which regulate the cerebral blood flow under changes in arterial $\mathrm{CO}_{2}$ pressure, endothelial $\mathrm{NO}$ production and changes in $\mathrm{CBF}$ itself.

Several considerations are made to extend the model in the following way: the point of extension deals with the assumptions which are made for NO reactivity. It is important to note that $\mathrm{NO}$ is also produced at other regions in brain and thus has an effect on the smooth muscle cells of, i.e. large cerebral arteries and veins, and yields a change in compliance and resistance of these vessels. There is also a change in stroke volume $\nu$, heart rate $b$ and systemic resistance $R_{\mathrm{s}}$ as a consequence of NO production at the vessel cells of central veins (i.e. vena cava), which has to be taken into account. However, NO is treated as an input quantity of the system. This means that the distinct sources of NO generation have not been modelled explicitly. A thorough model of $\mathrm{NO}$ generation needs to comprise a variety of cell types (endothelial cells, astrocytes, etc.) as well as a complicated system of subcellular structures. Thus the simplification of NO physiology, i.e. to consider NO "to be simply there", appears justified. A multiscale submodel of $\mathrm{NO}$ physiology would complicate the model as a whole substantially. A multiscale submodel would only be justified in terms of additional information if a spatial resolution of the cerebrovascular system were given as these subcellular events are governed by the local milieu. In the present model, variation of NO concentrations within physiologic bounds will provide the necessary information. 

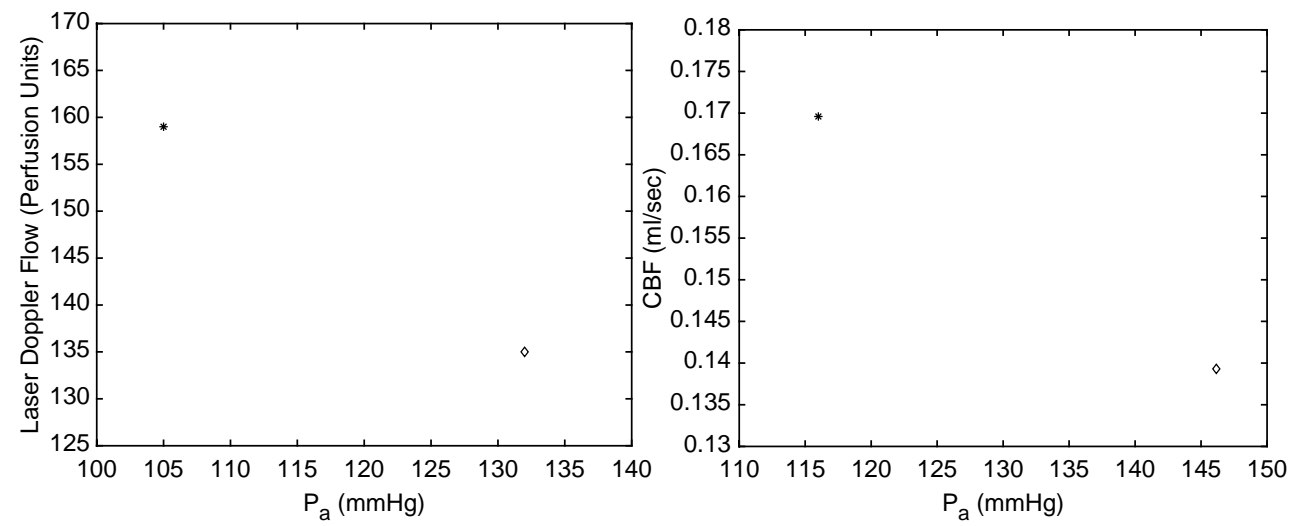

Figure 18. Left: measured data of Hudetz et al. [29], which show the effects of nitric oxide synthase inhibition with L-NAME on mean laser-Doppler flow and mean arterial pressure $P_{\mathrm{a}}$ in rat cerebral cortex. *, control; $\diamond$, L-NAME. Right: numerically simulated effect of L-NAME infusion and increased blood pressure $P_{\mathrm{a}}$ on CBF. The $26 \%$ increase in blood pressure and the $90 \%$ decrease in NO production rate yield an $17.8 \%$ decrease in CBF in comparison to the $15 \%$ decrease measured by Hudetz et al. [29].

\section{References}

[1] Ursino, M. and Lodi, C.A., 1998, Interaction among autoregulation, $\mathrm{CO}_{2}$ reactivity, and intracranial pressure: a mathematical model, American Journal of Physiology: Heart and Circulatory Physiology, 274, H1715-H1728.

[2] Ursino, M., Ter Minassian, A., Lodi, C.A. and Beydon, L., 2000, Cerebral hemodynamics during arterial and $\mathrm{CO}_{2}$ pressure changes: in vivo prediction by a mathematical model, American Journal of Physiology: Heart and Circulatory Physiology, 279, $\mathrm{H} 2439-\mathrm{H} 2455$.

[3] Ursino, M. and Lodi, C.A., 1997, A simple mathematical model of the interaction between intracranial pressure and cerebral hemodynamics, Journal of Applied Physiology, 82(4), $1256-1269$.

[4] Olufsen, M.S., Nadim, A. and Lipsitz, L.A., 2002, Dynamics of cerebral blood flow regulation explained using a lumped parameter model, American Journal of Physiology: Regulatory Integrative and Comparative Physiology, 282, R611-R622.

[5] Molino, P., Cerutti, C., Julien, C., Cuisinaud, G., Gustin, M.-P. and Paultre, C., 1998, Beat-to-beat estimation of windkessel model parameters in conscious rats, American Journal of Physiology, 274, H171-H177.

[6] Stevens, S.A., Lakin, W.D. and Goetz, W., 2003, A differentiable, periodic function for pulsatile cardiac output based on heart rate and stroke volume, Mathematical Biosciences, 182(2), 201-211.

[7] Harper, S.L., Bohlen, H.G. and Rubin, M.J., 1984, Arterial and microvascular contributions to cerebral cortical autoregulation in rats, American Journal of Physiology, 246, H17-H24.

[8] Muir, J.K. and Ellis, E.F., 1993, Cocaine potentiates the blood pressure and cerebral blood flow response to norepinephrine in rats, European Journal of Pharmacology, 249(3), 287-292.

[9] Iadecola, C., 1992, Does nitric oxide mediate the increases in cerebral blood flow elicited by hypercapnia?, Proceedings of the National Academy of Sciences USA, 89(9), 3913-3916.

[10] Malyshev, I.Y., Zenina, T.A., Golubeva, L.Y., Saltykova, V.A., Manukhina, E.B., Mikoyan, V.D., Kubrina, L.N. and Vanin, A.F., 1999, NO-Dependent mechanisms of adaptation to hypoxia, Nitric oxide: Biology and Chemistry, 3(2), 105-113.

[11] Yu, M., Sun, C.-W., Maier, K.G., Harder, D.R. and Roman, R.J., 2002, Mechanism of cGMP contribution to the vasodilator response to NO in rat middle cerebral arteries, American Journal of Physiology: Heart and Circulatory Physiology, 282, H1724-H1731.

[12] Arribas, S.M., Vila, E. and McGrath, J.C., 1997, Impairment of vasodilator function in basilar arteries from aged rats, Stroke, 28, $1812-1820$.

[13] Wang, Q., Pelligrino, D.A., Baughman, V.L., Koenig, H.M. and Albrecht, R.F., 1995, The role of neuronal nitric oxide synthase in regulation of cerebral blood flow in normocapnia and hypercapnia in rats, Journal of Cerebral Blood Flow and Metabolism, 15(5), $774-778$.

[14] Niwa, K., Lindauer, U., Villringer, A. and Dirnagl, U., 1993, Blockade of nitric oxide synthesis in rats strongly attenuates the CBF response to extracellular acidosis, Journal of Cerebral Blood Flow and Metabolism, 13(3), 535-539.

[15] Wang, Q., Pelligrino, D.A., Koenig, H.M. and Albrecht, R.F., 1994, The role of endothelium and nitric oxide in rat pial arteriolar dilatory responses to $\mathrm{CO}_{2}$ in vivo, Journal of Cerebral Blood Flow and Metabolism, 14, 944-951.

[16] Harada, M., Fuse, A. and Tanaka, Y., 1997, Measurement of nitric oxide in the rat cerebral cortex during hypercapnoea, NeuroReport, 8, 999-1002.

[17] Muchitsch, E.-M., Pichler, L. and Schwarz, H.P., 2004, Effects of $\alpha 1$-acid glycoprotein in combination with catecholamines on hemorrhagic hypovolemic shock in rats, Arzneim-Forsch/Drug Research, 54(2), 95-101.

[18] Mokrane, A. and Nadeau, R., 1998, Dynamics of heart rate response to sympathetic nerve stimulation, American Journal of Physiology, 275, H995-H1001.

[19] Gotoh, T.M., Fujiki, N., Tanaka, K., Matsuda, T., Gao, S. and Morita, H., 2004, Acute hemodynamic responses in the head during microgravity induced by free drop in anesthetized rats, American Journal of Physiology: Heart and Circulatory Physiology, 286, R1063-R1068.

[20] Baumbach, G.L., 1996, Effects of increased pulse pressure on cerebral arterioles, Hypertension, 27, 159-167.

[21] Sugiyama, T., Kawamura, K., Nanjo, H., Sageshima, M. and Masuda, H., 1997, Loss of arterial dilation in the reendothelialized area of the flow-loaded rat common carotid artery, Arteriosclerosis Thrombosis and Vascular Biology, 17, 3083-3091.

[22] Holtzer, S., Vigue, B., Ract, C., Samii, K. and Escourrou, P., 2001, Hypoxia-hypotension decreases pressor responsiveness to exogenous catecholamines after severe traumatic brain injury in rats, Critical Care Medicine, 29(8), 1609-1614.

[23] Mayhan, W.G. and Heistad, D.D., 1986, Role of veins and cerebral venous pressure in disruption of the blood-brain barrier, Circulatory Research, 59, 216-220.

[24] Hauerberg, J., Ma, X., Bay-Hansen, R., Pedersen, D.B., Rochat, P. and Juhler, M., 2001, Effects of alterations in arterial $\mathrm{CO}_{2}$ tension on cerebral blood flow during acute intracranial hypertension in rats, Journal of Neurological Anesthesia, 13(3), 213-221.

[25] Waschke, K.F., Riedel, M., Lenz, C., Albrecht, D.M., von Ackern, K. and Kuschinsky, W., 2004, Regional heterogeneity of cerebral blood flow response to graded pressure-controlled hemorrhage, Journal of Trauma, 56, 591-603.

[26] Schaller, C., Nakase, H., Kotani, A., Nishioka, T., Meyer, B. and Sakaki, T., 2002, Impairment of autoregulation following cortical venous occlusion in the rat, Neurological Research, 24, 210-214. 
[27] Engelborghs, K., Verlooy, J., Van Reempts, J., Van Deuren, B., Van de Ven, M. and Borgers, M., 1998, Temporal changes in intracranial pressure in a modified experimental model of closed head injury, Journal of Neurosurgery, 89, 796-806.

[28] Engelborghs, K., Haseldonckx, M., Van Reempts, J., Van Rossem, K., Wouters, L., Borgers, M. and Verlooy, J., 2000, Impaired autoregulation of cerebral blood flow in an experimental model of traumatic brain injury, Journal of Neurotrauma, 17(8), 667-677.
[29] Hudetz, A.G., Smith, J.J., Lee, J.G., Bosnjak, Z.J. and Kampine, J.P., 1995, Modification of cerebral laser-Doppler flow oscillations by halothane, $P_{\mathrm{CO}_{2}}$, and nitric oxide synthase blockade, American Journal of Physiology, 269, H114-H120.

[30] The Brain Trauma Foundation, 2000, The American Association of Neurological Surgeons. The joint section on neurotrauma and critical care. Guidelines for cerebral perfusion pressure, Journal of Neurotrauma, 17, 507-511. 


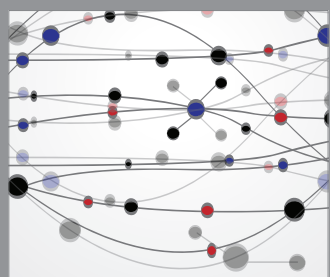

The Scientific World Journal
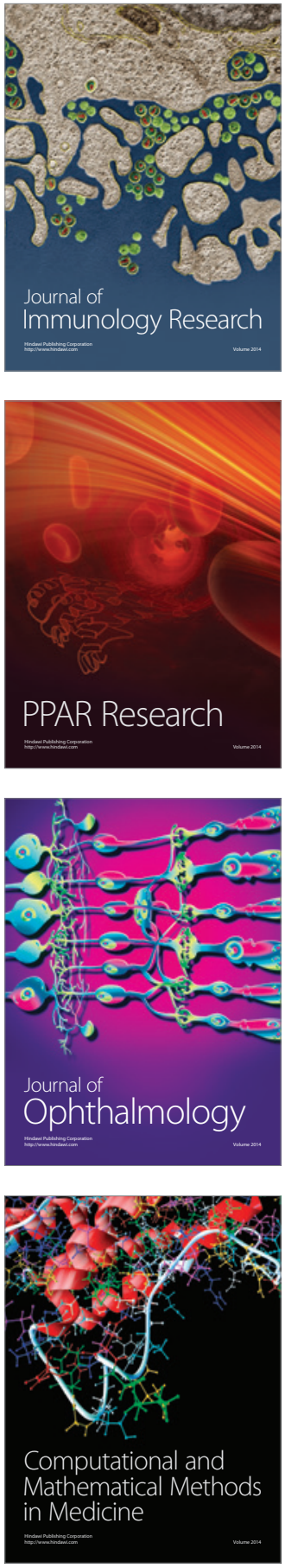

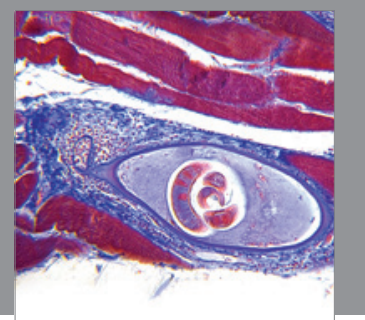

Gastroenterology

Research and Practice
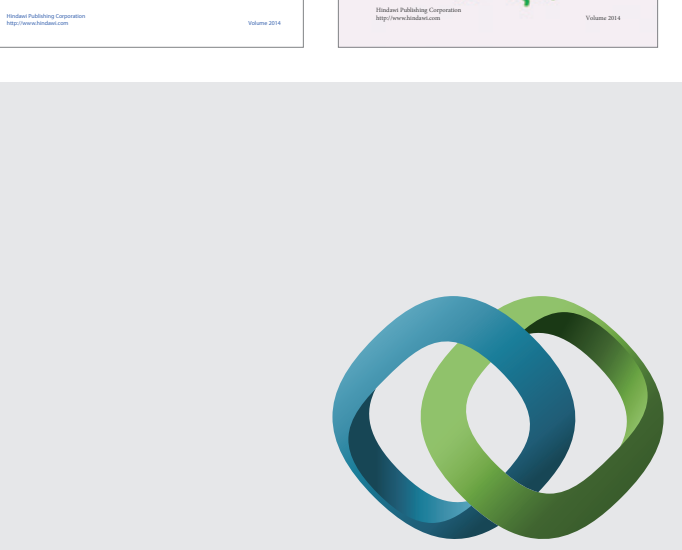

\section{Hindawi}

Submit your manuscripts at

http://www.hindawi.com
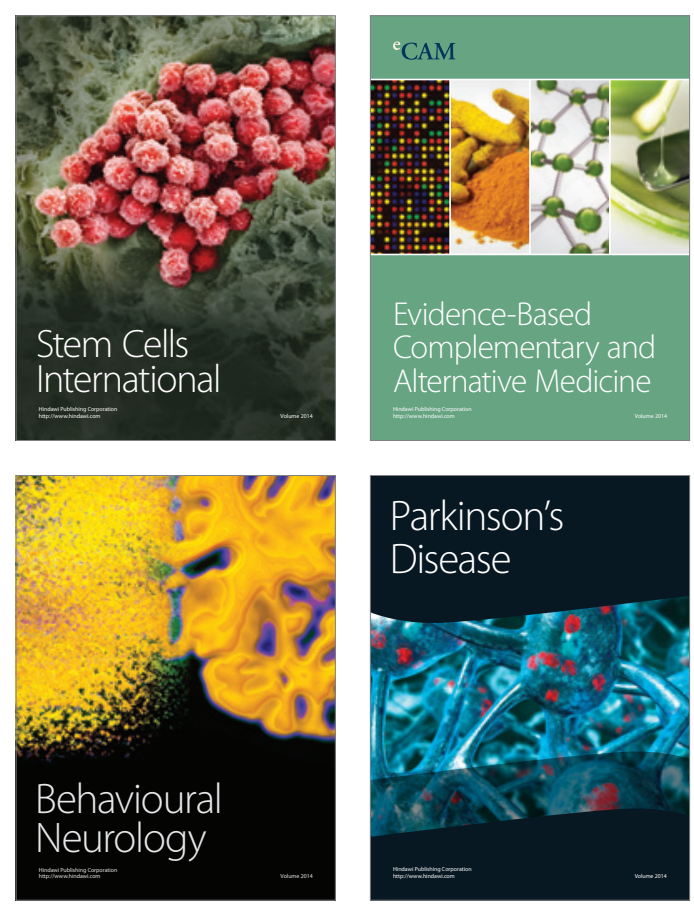

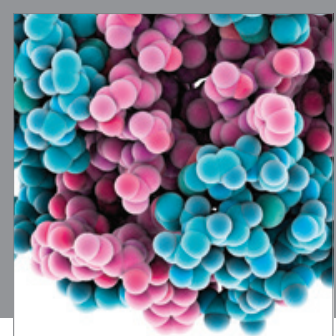

Journal of
Diabetes Research

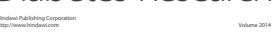

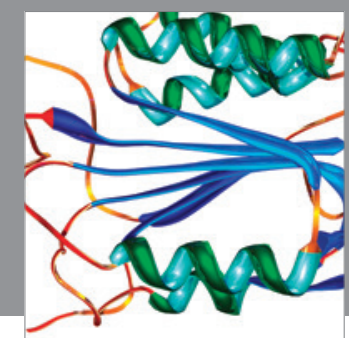

Disease Markers
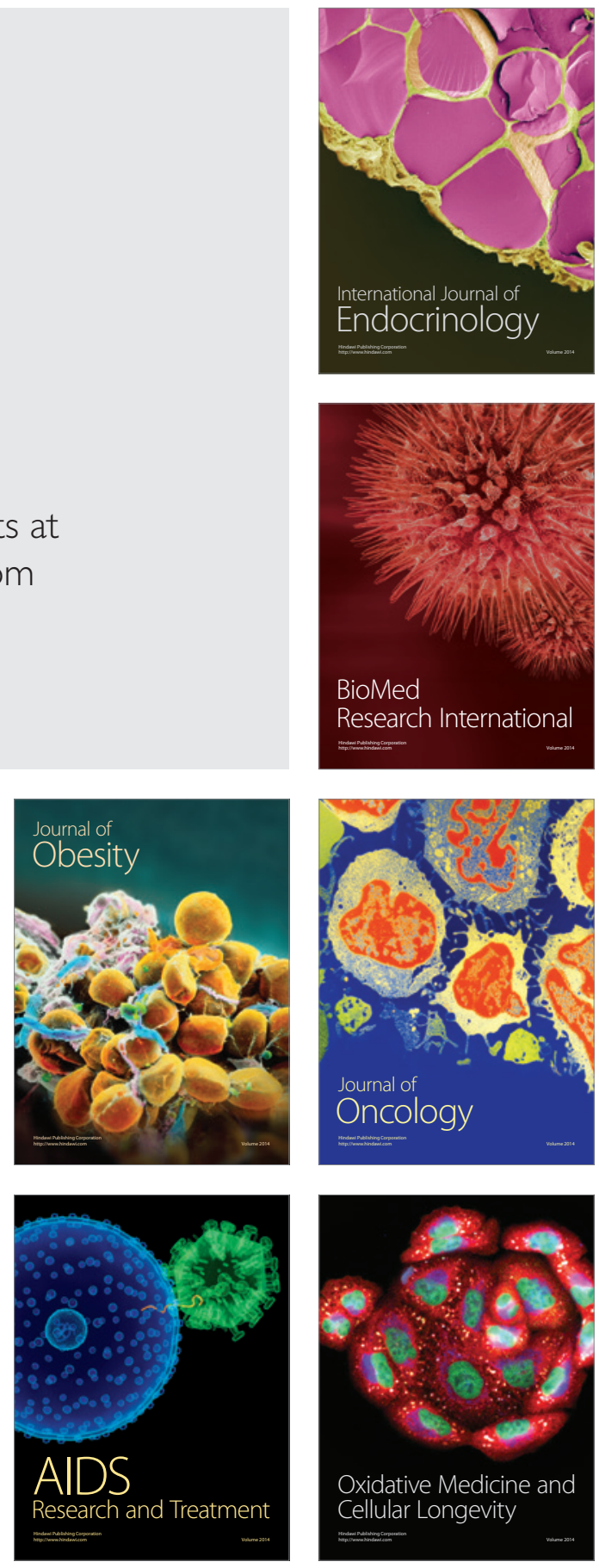